\title{
SUMOylation of ABCD3 restricts bile acid synthesis and regulates metabolic homeostasis.
}

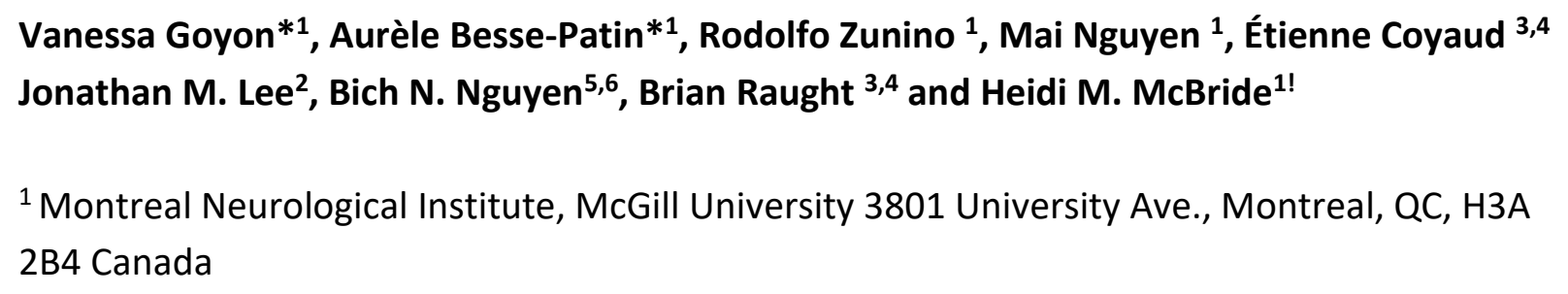


Mitochondrial anchored protein ligase (MAPL) has been shown to function as both a SUMO and ubiquitin ligase with multiple roles in mitochondrial quality control, cell death pathways and inflammation. To examine the global function of MAPL we generated a knockout mouse model and sought functional insight through unbiased BiolD, transcriptomics and metabolic analysis. MAPL KO mice are lean and highly insulin sensitive, ultimately developing fully penetrant, spontaneous hepatocellular carcinoma after 18 months. BiolD revealed the peroxisomal bile acid transporter ABCD3 as a primary MAPL interacting partner, which we show is SUMOylated in a MAPL-dependent manner. MAPL KO animals showed increased bile acid secretion in vivo and in isolated primary hepatocytes, along with robust compensatory changes in the expression of enzymes synthesizing and detoxifying bile acid. In addition, MAPL KO livers showed signs of ER stress and secreted high levels of Fgf21, the starvation hormone known to drive the reduction of white fat stores and promote insulin sensitivity. Lastly, during aging all MAPL KO mice developed hepatocellular carcinomas. These data reveal a major function for MAPL in the regulation of bile acid synthesis leading to profound changes in whole body metabolism and the ultimate generation of liver cancer when MAPL is lost. 


\section{Introduction}

Mitochondria are an essential signaling platform that contributes to cell fate decisions,

61 from cell cycle transitions to stem cell differentiation, T-cell activation, pathogen invasion,

62 starvation and more (Nunnari and Suomalainen, 2012). An underlying reason for the integration

63 of mitochondria within cellular signaling pathways is to signal the transcriptional and post-

64 transcriptional changes required to alter fuel consumption and/or metabolite generation that

65 drive cellular transitions. In this way signaling at mitochondria contributes to the global rewiring

66 of cellular metabolism in response to a variety of extracellular stimuli and intracellular cues. It is

67 becoming apparent that, akin to other signaling pathways, post-translational modifications

68 including phosphorylation, ubiquitination and SUMOylation play a central role in the assembly

69 and regulation of mitochondrial signaling complexes (Escobar-Henriques and Langer, 2014; He et al., 2020; Tait and Green, 2012; Tan and Finkel, 2020). The mechanistic details responsible for these modifications in mitochondrial signaling are however still largely unknown.

MAPL, a mitochondrial and peroxisomal anchored protein ligase (also called MUL1/GIDE/HADES/MULAN) (Jung et al., 2011; Li et al., 2015, 2008; Zhang et al., 2008) is a mitochondrial outer membrane protein carrying two transmembrane domains, a $\sim 40 \mathrm{kDa}$ intermembrane space loop and C-terminal cytosolic RING finger with both SUMO and ubiquitination activities. It is also targeted to peroxisomes in mitochondrial vesicles and is part of the shared peroxisome/mitochondrial proteome. MAPL has been shown to modulate diverse cellular events including mitochondrial division, mitophagy, inflammation and cell death (Ambivero et al., 2014; Barry et al., 2018; Prudent et al., 2015; Rojansky et al., 2016; Yun et al., 2014). A common feature of MAPL induced SUMOylation of substrates is to stabilize complex

81 formation or assembly, making it a prime candidate regulator of signaling platforms on

82 mitochondria and peroxisomes (Prudent et al., 2015).

To better understand the primary function of MAPL we have explored the proximity

84 interactors using unbiased BiolD approaches (Roux, 2013; Roux et al., 2012). In addition to the

85 core mitochondrial and peroxisomal fission machinery, the BiolD identified peroxisomal ABCD3

86 as an interacting partner and SUMOylation substrate of MAPL. ABCD3 was shown to transport

87 the late stage precursors, the C27-bile acid intermediates $3 \alpha, 7 \alpha$-dihydroxycholestanoic acid 


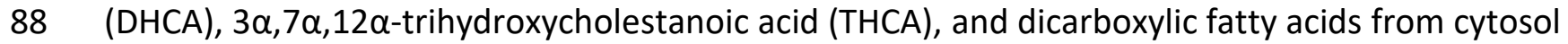
into peroxisomes (Ferdinandusse et al., 2015; Ranea-Robles et al., 2021). With the generation of a MAPL knock-out mouse model, we uncovered a critical role for this SUMO E3 ligase in restricting the activity of $A B C D 3$, highlighting new links to whole body metabolism. Further analysis of the MAPL deficient mice revealed increased hepatocyte proliferation, resistance to programmed cell death, and the development of hepatocellular carcinoma in aging mice. These data provide new insights into the post-translational regulation of bile acid metabolism within the liver, and the central role for peroxisomal SUMOylation in metabolic homeostasis.

Results.

\section{ABCD3/PMP70 is a MAPL substrate}

To identify MAPL interacting proteins we performed an unbiased proximity-dependent biotin identification (BiolD) in HEK293 cells (Roux, 2013; Roux et al., 2012). As expected, BiolD confirmed a robust interaction between MAPL and the fission GTPase DRP1 (Fig 1A) (Braschi et al., 2009; Neuspiel et al., 2008; Prudent et al., 2015). Indeed, essentially all of the mitochondrial fission machinery identified to date was identified in this analysis, including: the regulator of DRP1 recruitment AKAP1, the CAMP-dependent protein kinase type II-alpha regulatory subunit PRKAR2A, the DRP1 receptor MFF, the inverted formin INF2 (Kraus and Ryan, 2017), USP30, a

105 regulator of mitophagy and pexophagy (Bingol et al., 2014; Marcassa et al., 2018), and others. Also present was the antiviral signaling protein MAVS, an interaction we and others have 107 characterized previously (Doiron et al., 2017; Jenkins et al., 2013). Potential ubiquitin substrates 108 of MAPL such as MFN1, MFN2, AKT, HIF1 $\alpha$, or P53 were absent from the interactome at steady 109 state.

111 degradation, perhaps explaining the absence of any expected ubiquitin substrates of MAPL.

112 Therefore, we repeated the BiolD experiments in the presence of MG132 over 24 hours to

113 stabilize and accumulate any potential ubiquitinated MAPL-FlagBirA* substrates (Coyaud et al.,

114 2015) (Supplemental Table 1). Notably, the number of peptides identified for the vast majority 115 of MAPL interacting proteins remained unchanged in the presence of MG132, or were 
decreased, suggesting that MAPL does not target its primary binding partners for proteasomal

117 degradation. A few additional proteins were detected at very low levels after 24 hours of

118 MG132 treatment, with peptide counts ranging from 7 to24 (compared to 612 for AKAP1)

119 including BAX, MIRO1, BNIP3 and MFN2.

120 Unexpectedly, the top ranked MAPL binding protein detected in this analysis was the

121 peroxisomal bile acid transporter ABCD3/PMP70 (Fig 1A). We confirmed this result using

122 western blot analysis of biotinylated ABCD3 captured on streptavidin beads after incubation of

123 MAPL-BirA expressing cells with biotin (Supplemental Fig 1A). MAPL is delivered to

124 peroxisomes through a vesicular transport pathway from mitochondria (Braschi et al., 2010;

125 Neuspiel et al., 2008), where it plays a role in regulating peroxisomal fission (Mohanty et al.,

126 2021). However, broader roles of MAPL in peroxisomes are unknown. Given that ABCD3 has a

127 primary role in the generation of bile acids, we chose to validate the interaction and interrogate

128 the potential functional consequences of their binding within the liver of our $\mathrm{MAPL}^{-/-}$mouse

129 line (Doiron et al., 2017). Briefly, a parental C57BI/6J strain carrying floxed alleles at exon2 was

130 crossed with a CMV-Cre carrying strain to excise exon 2 in all cells, including the germline. After

131 backcrossing out the Cre gene, the resultant strain was a germline knock out for MAPL (Doiron

132 et al., 2017). We used these mice to test any interaction between native proteins by

133 immunoprecipitating endogenous MAPL from liver of control or $\mathrm{MAPL}^{-}$mice. While the anti-

134 MAPL antibodies did not efficiently precipitate endogenous MAPL, we still observed a MAPL-

135 dependent interaction with $A B C D 3$ from liver tissue (Fig 1B). We next monitored the

136 SUMOylation of $\mathrm{ABCD} 3$ within the liver of $\mathrm{MAPL}^{-/-}$mice. For this we isolated cytosol (Cyt) and

137 solubilized the heavy membrane $(\mathrm{HM})$ fraction from $\mathrm{MAPL}^{\mathrm{f} / \mathrm{f}}$ and $\mathrm{MAPL}^{-/-}$livers. These fractions

138 were incubated with agarose beads conjugated to peptides encoding the consensus SUMO

139 interacting motif (SIM) of the nuclear SUMO E3 ligases PIAS1-4 (Hecker et al., 2006). Indeed, we

140 observed an ABCD3 immunoreactive band on the SIM beads of control livers, which was almost

141 completely absent in livers from mice lacking MAPL (Fig 1C, quantification Supplemental Fig

142 1B). The molecular weight of ABCD3 upon the SIM beads was slightly shifted, suggesting a

143 mono-SUMOylation event. As a positive control MAPL was also required for the SUMOylation of

144 DRP1 (Fig 1C) (Braschi et al., 2009; Prudent et al., 2015). 
To further confirm whether MAPL was responsible for the SUMOylation of ABCD3 we generated adenovirus expressing MAPL-Flag, or a deletion construct lacking the C-terminal

147 RING finger required for SUMO conjugation or ubiquitination (MAPL- $R$ RING-FLAG). The viruses

148 (including an empty virus [rtTA] as negative control) were injected into the tail vein to target

149 the expression of MAPL specifically within the liver. ABCD3 SUMOylation was restored upon expression of full length MAPL, but not in MAPL- $\mathrm{RING-FLAG} \mathrm{(Fig} \mathrm{1D).} \mathrm{Given} \mathrm{the} \mathrm{interaction}$

151 between MAPL and ABCD3 observed within the BiolD and IP experiments, coupled with the 152 functional rescue of $A B C D 3$ SUMOylation upon re-expression of MAPL, these data establish MAPL as an essential regulator of ABCD3 SUMOylation.

We next examined the consequences of the loss of MAPL on the biochemical properties

155 of $A B C D 3$ in liver. Consistent with our evidence that MAPL does not generally regulate protein

156 turnover, the total mRNA and protein levels of $A B C D 3$ were unchanged in total liver extracts as

157 were Drp1 and Mfn2 protein levels (Supplemental Fig 1C, D). We also considered that

158 peroxisomal function, biogenesis or turnover may have been globally altered in $\mathrm{MAPL}^{-/-}$liver,

159 but observed no change in the expression levels of the peroxisomal proteins PEX14, ACOX1 and SCP2 (Supplemental Fig 1E).

As a half transporter, $A B C D 3$ assembles into both homo- and heterodimers (Guimarães

162 et al., 2004). To examine potential changes in the oligomeric assemblies of ABCD3 in the 163 absence of MAPL, we performed sucrose gradients from solubilized mouse liver extracts. As 164 previously described (van Roermund et al., 2014), the $70 \mathrm{kDa}$ ABCD3 protein migrated at a 165 higher molecular weight, consistent with a higher order oligomeric structure (Fig 1E).

166 Consistent with the abundance of ABCD3 in the MAPL BioID, MAPL co-migrates with ABCD3 in 167 fractions 5, 6 and 7 on the sucrose gradient. Notably, extracts isolated from $\mathrm{MAPL}^{-/}$mice 168 revealed a change in the migration pattern of $A B C D 3$, with $A B C D 3$ spreading throughout the 169 higher molecular weight fractions, indicating that MAPL SUMOylation activity is required to 170 maintain a stable oligomeric assembly of the ABCD3 transporter.

171 In sum, the data demonstrate that ABCD3 is SUMOylated by MAPL in liver tissue, a 172 process required to regulate a peroxisomal $A B C D 3$ complex. This provides the first evidence of a 173 post-translational modification in the regulation of $A B C D 3$ assembly. 
MAPL is required to gate the synthesis of bile acids in liver.

To determine whether the loss of ABCD3 SUMOylation may alter circulating bile acid

178 levels, we quantified total bile acids in plasma, and observed a 3-5-fold increase in the levels

179 within $\mathrm{MAPL}^{-}$mice (Fig 2A). Tail-vein injection of adenovirus expressing MAPL rescued the

180 elevation in circulating bile acids in a RING-dependent manner, demonstrating the requirement

181 for MAPL in repressing bile acid metabolism. (Fig 2B). We then employed quantitative mass

182 spectrometry using standards for over 40 selected bile acid conjugate species within circulation

183 and in liver (see Supplemental Fig 2A for schematic of bile acids) (Han et al., 2015). These data

184 revealed a significant decrease in the precursors DHCA and THCA within liver, with a

185 concomitant increase in mature bile acid species in both plasma and liver. This indicated that

186 the activity of bile acid synthesis was increased in these livers, leading to, for example beta-

187 muricholic (b-MCA) acid increasing from 10000 to $30000 \mathrm{fmol} / \mathrm{g}$ of liver tissue, and in plasma

188 from $600 \mathrm{nM}$ to $3500 \mathrm{nM}$ in the $\mathrm{MAPL}^{-/}$serum (Fig 2C, Supplemental Fig 2B, Supplemental

189 Table 2).

We then performed a transcriptome analysis of liver from 8 mice of each genotype aged

1915 months, revealing highly significant changes, most notably in the bile acid and steroid

192 hormone synthesis pathways of the liver (Fig 2D, E, Supplemental Table 3). Bile acid synthesis

193 in the liver occurs through 2 distinct pathways, the liver specific classical pathway requiring the

194 ER localized cholesterol 7-alpha-hydroxylase, CYP7A1 (black arrows, Fig 2F), and the alternative

195 or acidic pathway initiated in the mitochondria by sterol 27-hydroxylase CYP27A1 (red arrows,

196 Fig 2F) that oxidizes cholesterol to 27-hydroxycholesterol (Wang et al., 2021). The 27-

197 hydroxycholesterol derived in the mitochondria is then shuttled back to the ER where it is acted

198 upon by 25-hydroxycholesterol 7-alpha-hydroxylase, CYP7B1 to generate 5-cholesten-3 $\beta, 7 \alpha, 27$

199 triol, which is converted to the late stage C27 precursors DHCA and THCA for transport into the

200 peroxisome. Therefore, for complete synthesis of primary bile acids, the metabolites must flux

201 between the ER, mitochondria, peroxisomes and cytosol (Fig 2F). The transcriptome identified

202 Cyp7B1 as a major downregulated mRNA in $\mathrm{MAPL}^{-/-}$liver (Fig 2E), however there were no 
203 available antibodies to confirm this reduction at the protein level. Therefore, we examined the

204 protein levels of CYP27A1 and CYP7A1, representing each arm of the bile acid synthesis

205 pathway. The data showed that the initial enzyme CYP27A1 in the alternative (or acidic) bile

206 synthesis pathway was downregulated to $66 \%$ of control mice, consistent with a compensatory

207 adaptation to lower total bile acid synthesis. Although liver and serum bile acids were increased

208 significantly, the initiating enzyme of the classical pathway, CYP7A1 was unchanged (Fig 2G,

209 quantification Supplemental Fig 2C). We confirmed the transcriptome data further using qRT-

210 PCR from liver mRNA, showing a near loss of Hsd3b5 and Cyp7B1 mRNA, as well as a significant,

211 25\% reduction in Cyp27A1 mRNA (Supplemental Fig 2D). Cyp7A1 and Cyp8B1 were unchanged.

212 In contrast, there was an upregulation of proteins involved in detoxifying bile acid

213 intermediates and lipid soluble xenotoxins, including CYP3A11 and CYP4A14 (Fig 2D, E, G,

214 Supplemental Fig 2C, D) (Wagner et al., 2005), and UDP-glucuronidation transferase 1A12

215 (UGT1A12, also called 1A9, Fig 2E), which converts lipid soluble sterols, hormones or bilirubin to

216 water soluble, excretable metabolites (Bosma et al., 1994), all consistent with compensation to

217 limit toxicity from elevated bile acids, and reduce synthesis. We further confirmed that MAPL

218 depletion in liver was responsible for the near loss of $\mathrm{Hsd} 3 \mathrm{b5}$ and the upregulation of Cyp4A14,

219 as tail-vein injection of adenovirus expressing MAPL rescued the normal expression of these

220 proteins in a RING-dependent manner (Supplemental Fig 2E, F).

221 We examined the established components of the regulatory feedback loop that controls

222 Cyp7A1 expression and found that circulating FGF15 levels were unchanged (Supplemental Fig

223 2G) (Chiang, 2009). FGF15 is secreted from the ileum in response to the bile acids that recycle

224 across the ileum. In addition, the liver expression of the bile acid responsive Farnesoid Receptor

225 transcription factor FXR, (gene name Nr1h4) was also unchanged (Supplemental Fig $\mathbf{2 H}$ )

226 (Matsubara et al., 2013). Therefore, while we observe significant increases in bile acids in liver

227 and plasma, the sensing system for feedback regulation of the classical pathway remained

228 curiously unaltered.

229

230 Increased bile acid synthesis parallels increased FGF21 secretion; that can be uncoupled from

$231 \quad$ ER stress. 
Almost $90 \%$ of the cholesterol within the mouse liver is used to make bile, making this one of the most dominant biochemical cascades in liver (Wanders, 2013). An accumulation of

234 intracellular bile acids have been shown to result in ER stress, leading to a transcriptional response increasing expression of the detoxifying enzymes Cyp3A11 and Cyp4A14 (Bochkis et al., 2008), as we observed in $\mathrm{MAPL}^{-/-}$liver. An examination of ER stress markers revealed a robust increase in the phosphorylation of PERK, and CHOP expression in livers of $\mathrm{MAPL}^{-/}$ animals (Fig 3A, quantification Supplemental Fig 3A). Consistent with PERK activation, we observed the phosphorylation of a primary substrate, the translation initiation factor $2 \alpha$, EIF2 $\alpha$ (Fig 3B, quantification Supplemental Fig 3A) (Hetz, 2012). This reduces the translation of most mRNAs, allowing selective translation of the transcription factor ATF4. The upregulation of an ATF4 target gene (Salminen et al., 2017), Fgf21 mRNA was observed in the transcriptome analysis (Supplemental Table 3), and by qRT-PCR we observe a robust $\sim 30$ fold increase (Fig

244 3C), and a corresponding increase at the protein level in MAPL ${ }^{-1}$ liver (Fig 3D, quantification

245 Supplemental Fig 3B). Fgf21 mRNA was increased in other tissues 2-6-fold (Fig 3C). Importantly, 246 circulating levels of FGF21, quantified by ELISA showed a 12-fold increase in MAPL $\%$ mice (Fig 247 3E). Circulating FGF21 binds to heterotrimeric surface receptors comprised of FGFR1c, FGFR2c or FGFR3c, in complex with the $\beta$-Klotho receptors (Itoh, 2014; Owen et al., 2014). Initially thought to act primarily to signal the "browning" of white adipocytes, FGF21 binds receptors

250 within the suprachiasmatic nucleus (SCN) of the hypothalamus and the dorsal vagal complex of

251 the hindbrain (Bookout et al., 2013; Owen et al., 2014; Patel et al., 2015). Indeed the lean

252 phenotype resulting from FGF21 expression was shown to be independent of the uncoupler

253 UCP1 that is central to the browning of white adipocytes (Veniant et al., 2015). FGF21 binding

254 within the suprachiasmatic nucleus leads to dramatic alterations in circulating glucocorticoids,

255 altering circadian rhythm, thirst, blood pressure, and whole body metabolism (BonDurant and

256 Potthoff, 2018; Bookout et al., 2013; Pan et al., 2018; Song et al., 2018). Consistent with these

257 findings, we also observe a 4-fold increase in circulating corticosterone levels, and 10-fold 258 increase in liver of $\mathrm{MAPL}^{-/-}$mice (Supplemental Fig 3C). In addition, evidence in rodents has 259 shown FGF21 as a negative regulator of bile acid synthesis (Chen et al., 2018), again consistent 
with FGF21 upregulation within $\mathrm{MAPL}^{-/-}$mice playing a potentially compensatory role to reduce bile acid synthesis.

While there was chronic activation of ER stress within the MAPL $\%$ liver, the circulating levels of liver damage markers ALT and AST were only mildly increased. Therefore, ER stress did not appear pathological, and we observed no evidence of gross liver damage, steatosis or fatty liver upon histological examination (Fig 3F, Supplemental Fig 3D, E). As described above, any

266 liver damage resulting from ER stress may have been ameliorated through the compensatory 267 upregulation of detoxifying enzymes like CYP4A14 and CYP3A11 (Fig 2G). If the ER stress is 268 related to increased bile acid synthesis, it should be liver specific. To test this, we examined the 269 activation of CHOP and PERK in other tissues (Fig 3G). In addition to liver, we observed an

270 increase in the phosphorylation of PERK in the stomach, but this was not accompanied by an

271 increase in CHOP. However, there was no sign of ER stress in muscle, brain, spleen or

272 embryonic fibroblasts, consistent with a liver specific role of MAPL in the regulation of bile acids 273 and generation of ER stress.

As Fgf21 is a transcriptional target of ATF4, which is selectively translated during ER (or

275 mitochondrial) stress, it would follow that FGF21 expression should be dependent upon ER

276 stress. However, while tail vein rescue of MAPL expression showed a complete RING-dependent

277 restoration of circulating and liver Fgf21 mRNA and its protein levels, the ER stress remained

278 (Fig 3H,I,J, Supplemental Fig 3F). The tail-vein injection of empty adenovirus (rtTA) induced ER

279 stress in liver, potentially masking any rescue that may have resulted from MAPL expression

280 (Supplemental Fig 3G). Nevertheless, the experiment reveals an ER stress-independent

281 regulation of FGF21 expression that instead appears to directly parallel the levels of circulating

282 bile acids.

\section{$\mathrm{MAPL}^{-/-}$mice are lean}

286 A primary phenotype resulting from elevated levels of circulating FGF21 is a lean phenotype 287 involving both autocrine and paracrine signaling pathways between the liver, brain and 288 adipocytes (Flippo and Potthoff, 2021; Zhang et al., 2012). Consistent with these studies, mice 
lacking MAPL are of equal weight upon weaning, but rapidly reveal a lean phenotype, with an

B). Examining tissues revealed a loss in white adipocyte mass due to decreased lipid content as the primary cause of leanness, where body length and other tissue mass were unaltered (Fig 4C, D, E, Supplemental Fig 4C, D). We observed browning of white fat in $~ 30 \%$ of mice, when examining the expression of UCP1 in white fat by both qRT-PCR and western blot analysis (Fig

4F, Supplemental Fig 4E), however this did not correlate with the $100 \%$ of mice that were lean, consistent with primary targets of FGF21 in the brain. Given their metabolic phenotype, we performed insulin and glucose tolerance tests to monitor glucose handling and biogenesis. Injection of insulin led to an equivalent reduction in glycemia, however, $\mathrm{MAPL}^{-/-}$mice were unable to restore their glucose levels over the 120-minute time course (males in Fig 4G, females in Supplemental Fig 4F). Glucose tolerance tests revealed a more rapid glucose clearance in $\mathrm{MAPL}^{-/-}$vs. control mice, suggesting increased insulin sensitivity in MAPL-deficient animals (males in Fig 4H, females in Supplemental Fig 4G). Indeed, an analysis of circulating insulin revealed a 3-fold reduction in insulinemia in $\mathrm{MAPL}^{-/-}$compared to control mice (Fig 4I). In addition, glycogen storage in MAPL-deficient livers was also reduced by $\sim 50 \%$ as compared to control livers in ad libidum fed animals (Supplemental Fig 4H). Importantly, reconstitution of MAPL expression in liver via tail vain injection increased insulinemia, thereby suggesting that the changes in insulin levels stem from the liver rather than effects in muscle, pancreas, or the periphery (Fig 4J). Overall, these data show that $\mathrm{MAPL}^{-/-}$mice are profoundly insulin sensitive.

The loss of MAPL led to the chronic elevation of bile acids and FGF21. High levels of bile

312 acids have been shown to promote cell proliferation and stem cell activation through TGR5

313 receptor binding in multiple organs (Sorrentino et al., 2020) while elevated FGF21 levels extend

314 lifespan and improves metabolic health (Flippo and Potthoff, 2021; Zhang et al., 2012).

315 Histology revealed atypia in the livers of $\mathrm{MAPL}^{-/-}$animals, as early as 2 months, which increased

316 in severity with age, from scattered changes to pseudo-inclusions, dysplasia, and aberrant

317 mitotic events. (Supplemental 5A). This was accompanied by a $\sim 5$ and $\sim 15$-fold increase in 
318 hepatocyte proliferation in 2- and 7-month-old $\mathrm{MAPL}^{-/-}$relative to control mice, respectively as 319 evidenced by the Ki67 staining (Fig 5A). There was no obvious sign of steatosis or inflammation 320 within $\mathrm{MAPL}^{-/-}$livers, commonly linked to liver dysfunction.

Then, we aged these animals to determine the longer-term effects of these alterations.

322 While survival was only slightly reduced in aged $\mathrm{MAPL}^{-/-}$mice relative to wild-type littermates

323 (males shown Fig 5B, females in Supplemental Fig 5B), 87\% and 89\% ( $n=8$ and 9) of the MAPL ${ }^{-/}$

324 males and females, respectively, presented with liver cancer between 14-28 months (Fig 5C,

325 supplemental Fig $\mathbf{5 C}$ ). Histological analysis from 17 tumours in different mice (both males and

326 females) stained with H\&E and reticulin confirmed all had hepatocellular carcinoma, however

327 some of the tumours had mixed pathology (Fig 5D). In contrast, no littermate controls within

328 this cohort developed any malignancies.

329 These findings implicate MAPL within a pathway where it exerts a tumor suppressive

330 role in the liver. Tumor suppressors are also defined by their ability to drive or promote cell

331 death upon overexpression. Indeed we previously described critical roles for MAPL and the

332 SUMOylation of DRP1 in the process of apoptosis (Prudent et al., 2015), hinting that some of

333 the cancer phenotype may arise due to an inhibition in cell death. To test whether ectopic

334 expression of MAPL may promote cell death directly we infected a human liver cell line Huh7

335 with adenovirus expressing MAPL-Flag, MAPL- $\triangle$ RING-Flag SUMOylation-deficient mutant or the

336 empty vector (Ad-rtTA). Expression of wild-type but not SUMOylation-deficient mutant MAPL

337 led to cell death showing 4\% of cells remaining after 24 hours (Fig 5E). This was accompanied

338 by the cleavage of caspases 3 and 7, thus indicating that forced expression of MAPL induced cell

339 death (Fig 5F). Moreover, expression of SUMO competent MAPL in Rat2 fibroblasts stably

340 expressing oncogenic $\mathrm{H}-\mathrm{Ras}^{\mathrm{V} 12}$ also led to an arrest in anchorage-independent cell growth and

341 cell death initiation, as seen with PARP cleavage (Fig 5G). Therefore, ectopic expression of

342 MAPL promotes cell death and reduces neoplastic growth in vitro. Lastly, we examined the

343 capacity of $\mathrm{MAPL}^{-/}$primary hepatocytes to resist cell death induced in two distinct ways.

344 Infection of primary hepatocytes with truncated Bid (tBID) revealed that cells lacking MAPL

345 were more sensitive to this direct induction of death. However, induction of DNA damage upon 346 incubation with the DNA intercalating agent camptothecin showed complete resistance to cell 
347 death compared to littermate floxed hepatocytes. Therefore, while MAPL is not essential for

348 the steps driving apoptosis downstream of activated BAX, loss of MAPL is highly protective

349 against genotoxic stress. These data show that expression of MAPL is a driver of cell death, and 350 loss of MAPL offers significant resistant to cell death, consistent with its liver tumor suppressor 351 activity in vivo.

\section{Discussion.}

MAPL was first identified as a RING-finger containing ligase transported to peroxisomes from mitochondria in vesicular carriers, but its primary role there has been unclear. Here we present an unbiased interactome that identified previously described targets of MAPL, including Drp1 and MAVS (Braschi et al., 2009; Doiron et al., 2017; Prudent et al., 2015), which extends the list of new potential targets. This included nearly all of the machinery that regulates mitochondrial division, the ubiquitin protease USP30, and others. Previously described ubiquitin targets of MAPL were not identified in this interactome, and experiments performed in the presence of the proteasome inhibitor MG132 did not support a primary role for MAPL in the regulation of protein turnover. However, the identification of USP30 as a potential target hints that MAPL may modify USP30 directly, a deubiquitinase shown to target

364 Parkin substrates, reversing mitophagy and Parkin-mediated protein turnover (Bingol et al., 365 2014; Marcassa et al., 2018). In this way, reported effects of MAPL on protein turnover and 366 mitophagy may reflect indirect mechanisms.

367 While the BiolD identifies multiple potential targets for MAPL, the top hit was the 368 peroxisomal bile acid transporter, ABCD3. Our analysis of this interaction demonstrated that 369 ABCD3 is SUMOylated in a MAPL-dependent manner in vivo, a modification seen to regulate the 370 assembly into a higher molecular weight complex. This is the first documentation of

371 SUMOylation as a regulatory post-translational modification of the bile acid transport

372 machinery. Functionally, the loss of MAPL led to an increased production of bile acids from

373 liver, suggesting that the SUMO conjugated form of ABCD3 may act as a gate to inhibit

374 transport of the C27 precursors. This would be consistent with evidence for SUMO conjugation

375 acting as a gating mechanism of potassium transporters at the plasma membrane, among 
others. Future work is necessary to better define how SUMOylation of ABCD3 acts to stabilize

377 the oligomeric form and gate the channel.

378 The transcriptome analysis from liver also revealed a significant upregulation of Fgf21

379 mRNA, which was confirmed with qRT-PCR and at the protein level in liver and plasma.

380 Consistent with the elevation of circulating FGF21, $\mathrm{MAPL}^{-/-}$mice are lean and resistant to weight

381 gain on a high fat diet. FGF21 expression has been tightly linked to starvation and ER stress

382 (BonDurant and Potthoff, 2018), and ER stress was observed in MAPL ${ }^{-/-}$liver. However, while

383 tail vein rescue of MAPL expression in liver demonstrated that FGF21 expression was not linked

384 to ER stress in this system. Compensatory induction of hepatic FGF21 lead to insulin sensitivity,

385 leanness and diet-induced obesity resistance. Finally, our data do not yet distinguish whether

386 FGF21 expression resulted directly from the increase in bile acids through FXR (Cyphert et al.,

387 2012) or TGR5 (Donepudi et al., 2017) signaling, or whether it may relate to an unknown

388 functional target of MAPL in liver.

An interesting aspect of this study is that loss of MAPL led to an alteration in the

"alternative" pathway of bile acid synthesis without any change in the canonical, classical

391 pathway. Although the transcriptional regulation of the classical enzyme CYP7A1 is very well

392 studied (Chiang, 2009), the regulation of the more broadly expressed CYP27A1 and CYP7B1 is

393 less clear (Stiles et al., 2009). The latter enzymes are expressed in multiple tissues, playing roles

394 in sterol conversion and cholesterol homeostasis in different cell types. The regulation of

395 CYP27A1 expression is tissue specific and broad, with links to bile acid feedback, PPAR agonists, 396 insulin signaling, growth hormones and glucocorticoids (Lorbek et al., 2012). A recent study

397 showed a specific upregulation of CYP7B1 during cold exposure, leading to increased bile acid

398 secretion, altered microbiome and heat production (Worthmann et al., 2017). The mechanisms

399 regulating CYP7B1 expression in that study was not elucidated and we now reveal a role for

400 MAPL in modulating this specific arm of bile acid metabolism. In the case of $\mathrm{MAPL}^{-/}$mice, the

401 reduction in CYP7B1 and CYP27A1 appear to be compensatory, accompanying increases in

402 sterol clearance and detoxification pathways, likely minimizing liver damage. Circulating bile

403 acids have been shown to bind to the G-coupled protein receptor TGR5 within multiple organs

404 including adipocytes, brain, and gut (de Boer et al., 2018) . Therefore, the global phenotype of 
MAPL deficient mice will almost certainly be impacted by the elevated circulating bile in multiple ways, along with potential cell autonomous functions of MAPL in different tissues. Our study has focused first on the primary phenotype in liver where our study identified a critical function for MAPL in bile acid metabolism.

Ultimately, mice lacking MAPL also showed increased hepatocyte proliferation and later development of hepatocellular carcinoma. While this is consistent with emerging roles for bile

411 acids driving hepatocyte proliferation (Anakk et al., 2013), the circuitry of these events will also

412 be a focus of our future work.

MAPL/MUL1 has been previously linked to numerous cellular processes including

414 mitophagy (Ambivero et al., 2014; Li et al., 2015; Rojansky et al., 2016; Yun et al., 2014),

415 inflammation (Barry et al., 2018; Ni et al., 2017), antiviral (Doiron et al., 2017; Jenkins et al.,

416 2013), apoptosis (Prudent et al., 2015) and proliferation (Jung et al., 2011; Zhang et al., 2008),

417 where its activity allows the dynamic and rapid regulation of diverse signals. Our previous

418 studies demonstrated DRP1 as another substrate of MAPL, playing a key role in stabilizing the

419 oligomeric DRP1 during cell death. The fission machinery was identified within the BiolD here as

420 well and we demonstrate that ectopic expression of MAPL activated cell death pathways. Our

421 data also reveal that loss of MAPL restrict cell death pathways induced by genotoxic stress, that

422 may further contribute to tumor formation. Our future work will continue to investigate how

423 the tumor suppressive activity of MAPL functions in the regulation of global metabolism in liver,

424 and the potential relevance of MAPL function within human cancers. The MUL1 gene lies on

425 chromosome 1p36, which is a very commonly deleted region in human cancer. While there are

426 many genes within this region of the chromosomes, the $\mathrm{NCl}$ cancer genome atlas reports the

427 most common cancer with loss of MUL1 is cholangiocarcinoma. For now, the $\mathrm{MAPL}^{-1}$ mice

428 provide a new model to better understand the complex signaling pathways within in different

429 tissues, and under a variety of stimuli. 
Methods

434 Ethics Approval:

435 Animal experimentation was conducted in accordance with the guidelines of the Canadian

436 Council for Animal Care, with protocols approved by the Animal Care Committees of the

437 University of Ottawa and of McGill University.

\section{Generation of floxed MAPL KO mice:}

440 The targeting vector and the MAPL ${ }^{W T / f l o x}$ mice were generated by Ozgene (Australia). The

441 construct contained two loxP sequences inserted in intron 1 and intron 2 of the MAPL gene,

442 and two frt sites flanking the neomycin resistance selection cassette. The construct was

443 electroporated into C57BL/6 ES cell line, Bruce4 (Köntgen et al., 1993). Homologous

444 recombinant ES cell clones were identified by Southern hybridization and injected into BALB/cJ

445 blastocysts. Male chimeric mice were obtained and crossed to C57BL/6J females to establish

446 heterozygous germline offspring on pure C57BL/6 background. To remove the Neo-cassette

447 (neo), the MAPL ${ }^{W T / f l o x}$ mice were bred with homozygous FlpE-“deletor" C57BL/6 mice (Ozgene).

448 To generate $M A P L^{-/-}$mice, $M A P L^{f / f}$ mice were first bred with $C M V$-Cre carrying out mice (The

449 Jackson Laboratory). The resulting $M A P L^{+/-: C r e}$ were then bred with $M A P L^{f / f}$ animals. One quarter

450 of the offspring were $M A P L^{f /-}$. These heterozygous mice, devoid of the CMV-Cre gene, were

451 used as breeders: their offsprings were composed of $25 \% \mathrm{MAPL}^{-/}$animals, $25 \%$ of $M A P L^{f / f}$

452 animals used as littermate wild type controls and $50 \%$ of $M A P L^{f /-}$ animals used as littermate

453 heterozygous controls.

454 Genotyping was performed by PCR of tail DNA (extracted using the DNA Blood \& Tissue kit,

455 QIAgen, according to the manufacturer's instruction) using two different primer pairs (Primer1:

456 Fwd :5'-GGGAAGTGTGTGCCTTATG Rev: 5'-AATCCCAAGTCCACAGTGC and Primer2: Fwd: 5'-

457 CCTCAGAGTTCATTTATCC Rev: 5'-CCAACACCATCAAAAGGC). 
459 Mice were fed ad liditum either normal chow or a high fat diet (60\% fat, $20 \%$ proteins, $20 \%$

460 carbohydrate, Research Diets, for 10 weeks, starting at 12 weeks old). The food intake and body

461 weight of each mouse were recorded weekly.

462 Metabolic tests

463 Glucose tolerance tests (GTT) were performed after an overnight (16h fast). Blood glucose and

464 plasma insulin levels were measured after intra-peritoneal injection of glucose $(2 \mathrm{~g} / \mathrm{kg}$ of body

465 weight). Insulin tolerance tests (ITT) were performed after intra-peritoneal injection of human

466 insulin (0.5 U/kg) in 2-h-fasted mice.

467 Primary hepatocytes isolation, culture and glucose production

468 Primary hepatocytes were isolated from 12-to 16-week-old mice by 2-step liberase perfusion

469 (Liberase TL; MilliporeSigma \#05401020001) and 50\% Percoll gradient purification

470 (MilliporeSigma \#P1644). Cells were plated on collagen coated plates and cultured in

471 Dulbecco's modified Eagle's medium supplemented with $0.2 \%$ bovine serum albumin (fatty acid

472 free; Fisher Scientific), $25 \mathrm{mM}$ glucose, $2 \mathrm{mM}$ sodium pyruvate, $0.1 \mathrm{mM}$ dexamethasone, $1 \%$

473 penicillin/streptomycin, and $1 \mathrm{nM}$ insulin for up to 48 hours. To measure glucose production,

474 primary hepatocytes were switched to basic medium (DMEM with $0.2 \%$ BSA and $1 \mathrm{mM}$

475 glutamine, with no glucose, red phenol or sodium pyruvate) for $2 \mathrm{~h}$ to induce glycogenolysis

476 and deplete glycogen. Basic media containing $2 \mathrm{mM}$ lactate, $1 \mathrm{mM}$ pyruvate, $1 \mathrm{mM}$ glycerol

477 with or without $10 \mathrm{nM}$ glucagon (to promote gluconeogenesis) was exchanged and harvested

478 every hour for $3 \mathrm{~h}$. Glucose released was measured by enzymatic reaction (Hexokinase assay

479 \#GAHK20 MilliporeSigma) and normalized to protein content per well.

481 Adenovirus tail vein injection:

$4822 * 10^{9} \mathrm{PFU} / \mathrm{mouse}$ (MAPL-Flag) or $0.67 * 10^{9} \mathrm{PFU} / \mathrm{mouse}$ (MAPL- $\triangle$ RING-Flag and rtTA) of 483 adenoviruses were injected through the tail vein in a $100 \mu \mathrm{l}$ final volume of sterile saline 484 solution to 2-3 month old animals. At day 7 post injection, mice were starved overnight and fed 485 back for 3 hours (from 8 to 11AM). Blood was then collected by cardiac puncture and livers 486 were collected for further investigations. 


\section{Electrophoresis and immunoblot analysis:}

488 Tissues were homogenized in ice-cold lysis buffer (40 mM NaCl, 2 mM EDTA, 1 mM orthovanadate, $50 \mathrm{mM} \mathrm{NaF}, 10 \mathrm{mM}$ pyrophosphate, $10 \mathrm{mM}$ glycerolphosphate, $20 \mathrm{mM}$ NEM, 1\% Triton X-100, 50 mM Hepes, pH 7.4) supplemented with Complete protease inhibitor cocktail (Roche Molecular Biochemicals) in a borosilicate glass Dounce tissue grinder with tight pestle. After $20 \mathrm{~min}$ at $4^{\circ} \mathrm{C}$, homogenates were centrifuges at $20,000 \mathrm{~g}$ for $20 \mathrm{~min}$ at $4^{\circ} \mathrm{C}$, and the supernatants were collected. Protein extracts $(20 \mu \mathrm{g})$ were separated on a Tris-Glycine 4$20 \%$ gradient precast polyacrylamide gel (Invitrogen), and transferred to $0.22 \mu \mathrm{m}$ pore nitrocellulose membrane (Bio-Rad). Bands were visualized with Western-Lightning PLUS-ECL (Perkin-Elmer) with an INTAS ChemoCam (INTAS Science Imaging GmbH) and quantified with

MAPL was detected by rabbit polyclonal antibodies (HPA017681, 1:1,000, Sigma), PERK by rabbit polyclonal antibodies (100-401-962, 1:1,000, Rockland antibodies \& assays), phosphoPERK by rabbit monoclonal antibodies (3179, 1:1,000, Cell Signaling), elF2 $\alpha$ by mouse monoclonal antibodies (2103, 1:500, Cell Signaling), phospho-elF2 $\alpha$ by rabbit polyclonal antibodies (SAB4504388, 1:500, Sigma), Fgf21 by goat polyclonal antibodies (AF3057, 1:500,

504 R\&D systems), CHOP by rabbit polyclonal antibodies (5554, 1:500, Cell Signaling), BiP by rabbit 505 polyclonal antibodies (ADI-SPA-826-D, 1:1000, Enzo), CYP3A11 by rabbit polyclonal antibodies 506 (13384, 1:500, Cell Signaling), CYP4A14 by goat polyclonal antibodies (sc-46087, 1:500, Santa

507 Cruz), CYP7A1 by rabbit polyclonal antibodies (ab65596, 1:500, Abcam), CYP27A1 by rabbit 508 polyclonal antibodies (NBP2-16061, 1:500, Novus Biologicals), SUMO1 by mouse monoclonal 509 antibodies (332400, 1:1000, Invitrogen), Hsp60 by mouse monoclonal antibodies (sc-136291, 510 1:1000, Santa Cruz), Hsp70 by rabbit polyclonal antibodies (ab137680, 1:1000, Abcam), ABCD3 511 by mouse monoclonal antibodies (sab4200181, 1:1000, Sigma), DRP1 by mouse monoclonal 512 antibodies (611113, 1:1000, BD Transduction Labs), Mfn2 by rabbit polyclonal antibodies 513 (M6319, 1:1000, Sigma), UCP1 by a polyclonal antibody (U6382, 1:500, Sigma), ACOX1 by a 514 polyclonal antibody (10957-1-AP, 1:1000, Proteintech), SCP2 by a polyclonal antibody (14377-1515 AP, 1:1000, Proteintech), PEX14 by a polyclonal antibody (ABC142, 1:1000, Millipore), vinculin 
516 by a monoclonal antibody (V4505, 1:1000, Sigma), $\beta$-actin by rabbit polyclonal antibodies

517 (SAB4502543, 1:1,000, Sigma) and $\beta$-actin by mouse monoclonal antibodies (A2228, 1:1,000,

518 Sigma).

520 Cellular fractionation:

521 Liver was collected into ice-cold PBS and rinsed free of blood. It was minced into small pieces 522 and homogenized using a Dounce homogenizer (3-4 times, 1,600 rpm) into IB isolation buffer

523 (mannitol 200 mM, sucrose 68 mM, Hepes 20 mM pH 7.4, KCl 80 mM, EGTA 0.5 mM,

$524 \mathrm{Mg}$ (Acetate)2 $2 \mathrm{mM}$, 2-chloroacetamide $20 \mathrm{mM}$ and protease inhibitors 1X). Homogenate was

525 centrifuged at $800 \mathrm{~g}$ for $10 \mathrm{~min}$ to separate nuclear pellet from post-nuclear supernatant. The

526 nuclear pellet was resuspended into $2 \mathrm{ml}$ of IB buffer and centrifuged once again at $800 \mathrm{~g}$ for 10

527 min. Pellet was resuspended into $200 \mu \mathrm{I} \mathrm{IB}$ and kept as nuclear fraction. The post nuclear

528 supernatant was centrifuged at $1,000 \mathrm{~g}$ for $10 \mathrm{~min}$. The supernatant was kept and centrifuged

529 at $10,000 \mathrm{~g}$ for 20 min to separate mitochondrial heavy membrane pellet and post-

530 mitochondrial supernatant. Mitochondrial pellet was washed in $1 \mathrm{ml} \mathrm{IB}$ and centrifuged at

$53110,000 \mathrm{~g}$ for $10 \mathrm{~min}$. The final mitochondrial pellet was resuspended into $50 \mu \mathrm{I}$ IB and kept as

532 mitochondrial fraction. The post-mitochondrial supernatant was centrifuged at $200,000 \mathrm{~g}$ in

533 TLA-110 rotor (Beckman-Coulter) for $40 \mathrm{~min}$. Supernatant was kept as cytosolic fraction.

\section{Immunoprecipitation:}

536 For the MAPL immunoprecipitation, livers from 4 month old males were washed in ice-cold PBS 537 and homogenized in $5 \mathrm{ml}$ of lysis buffer $(50 \mathrm{mM}$ Tris, $150 \mathrm{mM} \mathrm{NaCl}, 0.5 \mathrm{mM}$ EDTA, $2 \mathrm{mM} \mathrm{MgCl}$, $5381 \%$ triton X-100, 20 mM NEM, pH 7.5) supplemented with Complete protease inhibitor cocktail 539 (Roche Molecular Biochemicals) in a borosilicate glass Dounce tissue grinder with tight pestle.

540 After $20 \mathrm{~min}$ at $4^{\circ} \mathrm{C}$ rocking, homogenates were centrifuged at $20,000 \mathrm{~g}$ for $20 \mathrm{~min}$ at $4^{\circ} \mathrm{C}$ and

541 supernatants were collected. $1 \mathrm{mg}$ of proteins (diluted at $2 \mathrm{mg} / \mathrm{ml}$ in lysis buffer) was pre-

542 cleared overnight at $4^{\circ} \mathrm{C}$, rocking with $100 \mu$ l of Dynabeads protein A beads (Life Technologies).

$543100 \mu \mathrm{l}$ of Dynabeads protein A beads (resuspended in $200 \mu \mathrm{l}$ of $0.1 \mathrm{M} \mathrm{NaP}, 0.08 \%$ Tween 20)

544 per condition were incubated overnight with $5 \mu \mathrm{g}$ of antibodies. The next day, antibodies were 
covalently bound to the beads using DMP crosslinker (Pierce) $20 \mathrm{mM}$, for 30 min at RT, rocking

in the dark) and crosslink reaction was stopped by $50 \mathrm{mM}$ Tris $\mathrm{pH} 7.5$ for $15 \mathrm{~min}$ at $\mathrm{RT}$, rocking.

547 Beads were washed 2 times with $100 \mu \mathrm{l}$ of $0.1 \mathrm{M}$ glycine $\mathrm{pH}$ 2.5. Precleared homogenates (1:20 was saved as starting material, SM) were applied on the antibodies-bound beads overnight at

$5494^{\circ} \mathrm{C}$, rocking. The next day, homogenates were removed from the beads and beads were washed 2 times with lysis buffer, 2 times with high salt buffer $(50 \mathrm{mM}$ Tris, $450 \mathrm{mM} \mathrm{NaCl}, 0.5$ mM EDTA, $2 \mathrm{mM} \mathrm{MgCl}$ 2, 0.05\% triton X-100, 20 mM NEM, pH 7.5) and 2 times with low salt

552 buffer (50 mM Tris, $150 \mathrm{mM} \mathrm{NaCl}, 0.5 \mathrm{mM}$ EDTA, $2 \mathrm{mM} \mathrm{MgCl}$ 2, 0.05\% triton X-100, $20 \mathrm{mM}$

553 NEM, pH 7.5). Proteins were eluted with $50 \mu$ of $0.1 \mathrm{M}$ glycine, pH 2.5, 0.5\% Triton X-100 (2

554 times). $20 \mu$ l of Tris $1 \mathrm{M} \mathrm{pH} 7.5$ were added to the elution.

\section{SIM-beads extracts from livers:}

557 Mouse livers were washed in ice-cold PBS and resuspended in cell fractionation buffer. Cells

558 were then broken with a cell cracker (EMBL-Heidelberg) using ball size 8.002. The samples were 559 centrifuged at $800 \mathrm{~g}$ at $4^{\circ} \mathrm{C}$ for $10 \mathrm{~min}$. Supernatants were re-cleared at $800 \mathrm{~g}$ for $5 \mathrm{~min}$ at $4^{\circ} \mathrm{C}$.

560 Post-nuclear supernatants were then centrifuged at $9,000 \mathrm{~g}$ for $20 \mathrm{~min}$ at $4^{\circ} \mathrm{C}$, in order to pellet 561 heavy membrane fraction (supernatant is the cytosolic fraction). The pellets were washed and 562 re-centrifuged for a further $10 \mathrm{~min}$ at 9,000 g. To heavy membrane and cytosolic fractions,

563 Triton X-100 was added up to $1 \%$ concentration, followed by incubation for 20 min at $4^{\circ} \mathrm{C}$, 564 rocking. The fraction lysates were then centrifuged for $45 \mathrm{~min}$ at $200,000 \mathrm{~g}$ at $4{ }^{\circ} \mathrm{C}$. Supernatants 565 were then collected and protein concentration determined ( $80 \mu \mathrm{g}$ total lysate fraction of each 566 type were separated to run in gel as starting material). Then $40 \mu$ of SIM beads (AM-200,

567 Boston Biochemicals) were added to each type of total lysate fractions (containing 0.5-1 mg of 568 proteins) and incubated for at least 1.5 hours at $4^{\circ} \mathrm{C}$, rocking, followed by centrifugation at $56914,000 \mathrm{~g}$ for $2 \mathrm{~min}$ at $4^{\circ} \mathrm{C}$. Beads were then washed 5 times with cell fractionation buffer 570 containing $1 \%$ Triton X-100. After the last wash was discarded, $1 \mathrm{X}$ Laemmli sample buffer was 571 added to the solid beads and run in acrylamide gel, together with the starting material. 
574 HEK293T-REX cells stably expressing either BirA or Flag-MAPL-BirA were maintained in DMEM

575 (Wisent) containing 10 \% FBS (Wisent), 2 mM L-glutamine, non-essential amino acids and 1 mM

576 sodium pyruvate (Life Technologies). The expression of BirA and Flag-MAPL BirA was induced

577 with $1 \mathrm{ug} / \mathrm{ml}$ tetracycline (Sigma) for 24 hours in culture at $37^{\circ} \mathrm{C}$, accompanied by $50 \mu \mathrm{M}$ biotin

578 (Sigma) final concentration. After the incubation, the cells on plates were washed 3 times in

579 PBS, then they were scrapped on ice and lysed for 20 min in buffer: $10 \mathrm{mM}$ Hepes pH 7.4, 200

$580 \mathrm{mM} \mathrm{NaCL}, 0.5 \mathrm{mM}$ EDTA, $2 \mathrm{mM} \mathrm{MgCL2}, 1 \%$ Triton-X100. Lysates were centrifuged (20,000 g at

$58144^{\circ} \mathrm{C}$ for $\left.15 \mathrm{~min}\right)$, normalized for protein concentration and incubated with streptavidin-agarose

582 beads (Life Technologies) for 1.5 hour rocking at $4^{\circ} \mathrm{C}$. Beads were centrifuged, washed 3 times

583 with lysis buffer, mixed with 1 X Laemmli buffer, and loaded onto a gel, along with starting

584 material. Then electrophoresis was performed, and proteins were transferred to nitrocellulose

585 membranes. Expression of Flag-BirA-MAPL, as well other candidate proteins for interacting with

586 MAPL, was determined by western blot with a series of antibodies.

Sucrose gradient:

590 Livers from 2-month-old males were washed in ice-cold PBS and homogenized in $3 \mathrm{ml}$ of

591 homogenization buffer (50 mM Tris, $150 \mathrm{mM} \mathrm{NaCl}, 0.5 \mathrm{mM}$ EDTA, $2 \mathrm{mM} \mathrm{MgCl}$, $20 \mathrm{mM}$ NEM)

592 supplemented with Complete protease inhibitor cocktail (Roche Molecular Biochemicals). A

593 fraction of the homogenates was sonicated in order to quantify protein content. Homogenates

594 were diluted in homogenization buffer to $4.7 \mathrm{mg} / \mathrm{ml} .500 \mu \mathrm{l}$ of homogenate at $4.7 \mathrm{mg} / \mathrm{ml}$ were 595 added to $500 \mu \mathrm{l}$ of homogenization buffer containing $1 \%$ DDM. After $20 \mathrm{~min}$ at $4^{\circ} \mathrm{C}$ rocking,

596 homogenates were centrifuged $20 \mathrm{~min}$ at $4^{\circ} \mathrm{C}$ at $14,000 \mathrm{rpm}$. Supernatants were collected, and

597 protein content determined. $250 \mu \mathrm{g}$ of proteins were loaded on the top of the $10-50 \%$ sucrose

598 linear gradient $\left(1800 \mu \mathrm{l}, 200 \mu \mathrm{l}\right.$ of each) and centrifuged for 4 hours at $4^{\circ} \mathrm{C}$, at 180,000 g. 12

599 fractions were collected and $75 \mu$ I of the different fractions were loaded on a $10 \%$ acrylamide

600 gel.

601

602 Blood analysis: 
603 Each tube was added with $250 \mu \mathrm{L}$ acetonitrile and the samples were homogenized again,

604 followed by centrifugation at $15000 \mathrm{rpm}$ and $10 \mathrm{C}$ for $5 \mathrm{~min} .200 \mu \mathrm{L}$ of the supernatants were

605 mixed with $50 \mu \mathrm{L}$ of the same IS solution, followed by PD-SPE using the same procedure as done

606 for mouse serum. The residues were reconstituted in $200 \mu \mathrm{L}$ of $50 \%$ methanol.

$60720 \mu \mathrm{L}$ of each of the above samples was injected onto a 15-cm long C18 UPLC column for

608 quantitation of bile acids by UPLC-(-)ESI/MRM/MS with negative-ion mode detection and with

609 water-acetonitrile-formic acid as the mobile phase for binary gradient elution, using the same

610 method as described in the publication. UPLC-MRM/MS runs were performed on a Dionex

611 Ultimate 3000 UPLC system coupled to a 4000 QTRAP triple-quad mass spectrometer.

612 Concentrations of the detected bile acids were calculated with internal standard calibration

613 from calibration curves prepared for individual compounds. For concentration calculation, the

61414 D-labeled bile acids were used as IS for their corresponding non-D-labeled forms. For the bile

615 acids, THCA and DHCA, for which there were no D-labeled analogues as IS, chenodeoxycholic-

616 D4 acid was used as the common IS for quantitation of the unconjugated bile acids, THCA and

617 DHCA; tauro-CDCA-D4 was used as the common IS for quantitation of the taurine-conjugated

618 species; glyco-deoxycholic-D4 acid was used as the common IS for quantitation of the glycine-

619 conjugated species.

620 Concentrations of the following bile acids were also estimated in this analysis: glyco- $\omega-\mathrm{MCA}$,

621 glyco- $\alpha-$ MCA, glyco- $\beta$-MCA, glyco- $\lambda$-MCA (also as glyco- $\gamma-$ MCA or glycohyocholic acid) or glyco-

622 allocholic acid. Since there were no standard substances for these compounds, their

623 concentrations were calculated from the calibration curve of glycocholic acid.

624 Another $20 \mu \mathrm{L}$ of each of the same samples was injected again onto the same C18 UPLC column

625 for UPLC-MRM/MS quantitation of corticosterone, but with positive-ion (+) mode detection.

\section{Illumina}

628 Total RNAs from the liver of 3 mice from each strain ( 5 months old) were isolated using the 629 TRIzol kit, following manufacturers protocols (Invitrogen), as described bellow. RNAs were 630 quantified using a NanoDrop Spectrophotometer ND-1000 (NanoDrop Technologies, Inc.) and 
631 its integrity was assessed using a 2100 Bioanalyzer (Agilent Technologies). Double stranded

632 cDNA was synthesized from 250ng of total RNA, and in vitro transcription was performed to

633 produce biotin-labeled cRNA using Illumina ${ }^{\circledR}$ TotalPrep RNA Amplification Kit, according to

634 manufacturer's instructions (Life Technologies). The labeled cRNA was then normalized at

635 1500ng and hybridized on Mouse WG-6, v.2 according to Illumina's Whole-Genome Gene

636 Expression Direct Hybridization Assay Guide. The BeadChips were incubated in an Illumina

637 Hybridization oven at $58^{\circ} \mathrm{C}$ for 14 to 20 hours at a rocking speed of 5 . Beadchips were washed

638 also according to Illumina's Whole-Genome Gene Expression Direct Hybridization Assay Guide

639 and scanned on an Illumina iScan Reader. RNA from each mouse was sequenced in triplicate.

640 Results were analyzed using the FlexArray software (provided by Genome Quebec). Volcano

641 plot was calculated using a 2 fold increase and decrease lower limit, with $\mathrm{p}$ values lower or

642 equal to 0.05 .

BiolD

645 BiolD (Roux et al., 2012) was carried out essentially as described previously (Comartin et al., 646 2013). In brief, the full-length human MAPL (BC014010) coding sequence was amplified by PCR

647 and cloned into a pcDNA5 FRT/TO BirA*FLAG expression vector (MAPL-Ascl_Fwd:

648 tataGGCGCGCCaATGGAGAGCGGAGGGCGGCCCTCG; MAPL-NotI_Rev:

649 ttaaGCGGCCGCGCTGTTGTACAGGGGTATCACCCG). Using the Flp-In system (Invitrogen), 293T-

650 REx Flp-In cells stably expressing MAPL-BirA*Flag were generated. After selection (DMEM +

$65110 \% \mathrm{FBS}+200 \mu \mathrm{g} / \mathrm{ml}$ hygromycin B), $10 \times 150 \mathrm{~cm}^{2}$ plates of subconfluent $(60 \%)$ cells were

652 incubated for 24 hours in complete media supplemented with $1 \mu \mathrm{g} / \mathrm{ml}$ tetracycline and $50 \mu \mathrm{M}$

653 biotin. Five plates were treated with 5 MM MG132. Cells were collected and pelleted (2000 rpm,

$6543 \mathrm{~min})$, the pellet was washed twice with PBS, and dried pellets were snap frozen. Pellets were

655 lysed in $10 \mathrm{ml}$ of modified RIPA lysis buffer (50 mM Tris- $\mathrm{HCl}, 150 \mathrm{mM} \mathrm{NaCl}, 1 \mathrm{mM}$ EDTA, $1 \mathrm{mM}$

656 EGTA, 1\% Triton X-100, 0.1\% SDS, 1:500 protease inhibitor cocktail, 250U Turbonuclease, pH

657 7.5) at $4^{\circ} \mathrm{C}$ for 1 hour, then sonicated to completely disrupt visible aggregates. The lysates were

658 centrifuged at $35,000 \mathrm{~g}$ for $30 \mathrm{~min}$. Clarified supernatants were incubated with $30 \mu \mathrm{l}$ packed,

659 pre-equilibrated Streptavidin-sepharose beads at $4^{\circ} \mathrm{C}$ for 3 hours. Beads were collected by 
660 centrifugation, washed 6 times with $50 \mathrm{mM}$ ammonium bicarbonate $\mathrm{pH}$ 8.2, and treated with

661 TPCK-trypsin (16 hours at 37C). The supernatant containing the tryptic peptides was collected

662 and lyophilized. Peptides were resuspended in $0.1 \%$ formic acid and $1 / 6^{\text {th }}$ of the sample was

663 analyzed per MS run.

$664 \quad$ Liquid chromatography (LC) analytical columns (75 $\mu \mathrm{m}$ inner diameter) and pre-columns

665 (100 $\mu \mathrm{m}$ ID) were made in-house from fused silica capillary tubing from InnovaQuartz and

666 packed with $100 \AA \mathrm{C}_{18}$-coated silica particles. LC-MS/MS was conducted using a $120 \mathrm{~min}$

667 reversed-phase buffer gradient running at $250 \mathrm{nl} / \mathrm{min}$ (column heated at 35C) on a Proxeon

668 EASY-nLC pump in-line with a hybrid LTQ-Orbitrap Velos mass spectrometer. A parent ion scan

669 was performed in the Orbitrap, using a resolving power of 60000 . Simultaneously, up to the 20

670 most intense peaks were selected for MS/MS (minimum ion count of 1000 for activation) using

671 standard CID fragmentation. Fragment ions were detected in the LTQ. Dynamic exclusion was

672 activated such that MS/MS of the same $\mathrm{m} / \mathrm{z}$ (within a $10 \mathrm{ppm}$ window, exclusion list size 500)

673 detected 3 times within $45 \mathrm{sec}$ were excluded from analysis for $30 \mathrm{sec}$. For protein

674 identification, .RAW files were converted to the mzXML format using Proteowizard, then

675 searched using X!Tandem against human RefSeq Version 45 (containing 36113 entries). Search

676 parameters specified a parent MS tolerance of $15 \mathrm{ppm}$ and an MS/MS fragment ion tolerance

677 of $0.4 \mathrm{Da}$, with up to 2 missed cleavages allowed for trypsin. Oxidation of the methionine was

678 allowed as a variable modification. Data were analyzed using the trans-proteomic pipeline via

679 the ProHits 2.0.0 software suite. Proteins identified with a ProteinProphet cut-off of 0.85

680 (corresponding to $\leq 1 \%$ FDR) were analyzed with SAINT Express v.3.3. Sixteen control runs were

681 used for comparative purposes, comprising 8 runs of BiolD conducted on untransfected 293T-

682 REx cells. In each case, 4 runs were conducted on untreated cells, and 4 runs were conducted in

683 cells treated with MG132, as above. The 16 controls were collapsed to the highest 4 spectral

684 counts for each hit. All raw mass spectrometry data have been uploaded to the MassIVE archive

685 (ucsd.edu), ID: MSVxxxx, password: MAPL. 
689 Formaldehyde-fixed, paraffin-embedded tissues were cut into $4 \mu \mathrm{m}$ sections and stained with

690 hematoxylin and eosin (H\&E).

691

692

\section{RNA isolation and qRT-PCR}

693 Total RNAs from various tissues were prepared using TRIzol (Invitrogen). They were treated

694 with DNAse (New England Biolabs), then reverse transcribed with random primers using the

695 High Capacity sDNA Reverse Transcription Kit (Life Technologies) as described by the

696 manufacturer. Before use, RT samples were diluted 1:5. Gene expression was determined using

697 assays designed with the Universal Probe Library (UPL) from Roche

698 (www.universalprobelibrary.com). For each qPCR assay, a standard curve was performed to 699 ensure the efficacity of the assay is between $90 \%$ and $110 \%$. qPCR reactions were performed

700 using 5-25 ng of cDNA samples, the TaqMan Advanced Fast Universal PCR Master Mix (Life

701 Technologies), $2 \mu \mathrm{M}$ of each primer and $1 \mu \mathrm{M}$ of the corresponding UPL probe. The Viia7 qPCR

702 instrument (Life Technologies) was used to detect the amplification level and was programmed

703 with an initial step of $3 \mathrm{~min}$ at $95^{\circ} \mathrm{C}$, followed by 40 cycles of: $5 \mathrm{sec}$ at $95^{\circ} \mathrm{C}$ and $30 \mathrm{sec}$ at $60^{\circ} \mathrm{C}$.

704 All reactions were run in triplicate and the average values of Cts were used for quantification.

705 The relative quantification of target genes was determined using the $\Delta \Delta C T$ method. Briefly, the

706 Ct (threshold cycle) values of target genes were normalized to an endogenous control gene

$707\left(\Delta C T=\mathrm{Ct}_{\text {target }}-\mathrm{Ct} \mathrm{CTRL}\right)$ and compared with a calibrator: $\Delta \Delta \mathrm{CT}=\Delta \mathrm{Ct}_{\text {sample }}-\Delta \mathrm{Ct}_{\text {Calibrator. }}$ Relative

708 expression (RQ) was calculated using the Sequence Detection System (SDS) 2.2.2 software

709 (Applied Biosystems) and the formula is $R Q=2^{-\Delta \Delta C T}$.

710 qRT-PCR primers used (5' to 3'):

711

\begin{tabular}{|l|l|l|l|}
\hline Gene Symbol & UPL probe & Fwd & Rev \\
\hline Fgf21 & 67 & agatggagctctctatggatcg & gggcttcagactggtacacat \\
\hline Ppara & 41 & cacgcatgtgaaggctgtaa & gctccgatcacacttgtcg \\
\hline Acadl & 75 & gcttatgaatgtgtgcaactcc & ccgagcatccacgtaagc \\
\hline Ppargc1a & 29 & gaaagggccaacagagaga & gtaaatcacacggcgctctt \\
\hline
\end{tabular}




\begin{tabular}{|l|l|l|l|}
\hline Cpt1b & 92 & gagtgactggtgggaagaatatg & gctgcttgcacatttgtgtt \\
\hline Acadm & 110 & agtacctgtggagaagctgat & tcaatgtgctcacgagctatg \\
\hline Ucp1 & 34 & ggcctctacgactcagtcca & taagccggctgagatcttgt \\
\hline Ucp2 & 2 & acagccttctgcactcctg & ggctgggagacgaaacact \\
\hline Ucp3 & 69 & tacccaaccttggctagacg & gtccgaggagagagcttgc \\
\hline Hsd3b5 & 17 & cgcttccagacagaccatc & gatgaatgttggcacactgg \\
\hline Cyp7b1 & 99 & aattggacagcttggtctgc & ttctcggatgatgctggagt \\
\hline $\begin{array}{l}\text { Cyp27a1 } \\
\text { Cyp7a1 }\end{array}$ & 27 & tctaccaccttgccttggaa & gcagtgtcctcaggaatgg \\
\hline Cyp8b1 & 85 & gatcctctgggcatctcaag & agaggctgctttcattgctt \\
\hline Cyp3a1 & 53 & tcctgagcttattcggctaca & cggaacttcctgaacagctc \\
\hline Cyp4a14 & 7 & gggactcgtaaacatgaactttt & ccatgtcgaatttccataaacc \\
\hline Cyp2b9 & 91 & catggcggactctgtcaata & gatctccagagggtggtcct \\
\hline Nr1h4 & 100 & ggaatgggaaagcggagt & gaagagaaaggtgggatccag \\
\hline Abcd3 & 91 & caaaatgactcaggaggagtacg & tccttgatgtattgtctgtctgg \\
\hline
\end{tabular}

\section{Statistical analysis}

714 Normal distribution and homoscedasticity of data were tested by Shapiro-Wilks and Bartlett

715 tests respectively. Parametric tests were used if distributions normal and variances equal.

716 Student t-test was used to compare 2 groups on 1 variable. One-way analysis of variance

717 (ANOVA) for univariate multiple comparisons or Two-way ANOVA (for bivariate comparisons)

718 were followed by Tukey's honest significant difference post-hoc test. Statistical analyses were

719 performed using GraphPad Prism software (San Diego, CA). Threshold for statistical significance

720 was $P<0.05$.

721 All values are expressed as mean \pm SEM 


\section{Acknowledgements}

725 This study was funded by Canadian Institute of Health Research and the Canadian Cancer

726 Society Research Institute (to HMM; CIHR\#68833, CCSRI\#702139). Work in the BR lab was

727 funded by ClHR \#130340. HMM holds the Canada Research Chair in Mitochondrial Cell Biology.

728 BR holds the Canada Research Chair in Proteomics and Molecular Medicine. ABP was supported

729 by a postdoctoral fellowship from Fonds de Recherche Québec - Santé. The authors would like

730 to thank the IRIC for qRT-PCR services and Ozgene (Australia) for services in the design and

731 generation of the floxed MAPL strain. We also thank Dr. Atilla Omeroglu (McGill University) for

732 help with histological analysis, Nancy Braverman (McGill University) for advice on bile acid

733 metabolism, and Tharan Srikumar for mass spectrometry technical assistance and the MNI

734 animal care services. 


\section{References}

Ambivero, C.T., Cilenti, L., Main, S., Zervos, A.S., 2014. Mulan E3 ubiquitin ligase interacts with multiple E2 conjugating enzymes and participates in mitophagy by recruiting GABARAP. Cell Signal 26, 2921-2929. https://doi.org/10.1016/j.cellsig.2014.09.004

Anakk, S., Bhosale, M., Schmidt, V.A., Johnson, R.L., Finegold, M.J., Moore, D.D., 2013. Bile Acids Activate YAP to Promote Liver Carcinogenesis. Cell Reports 5, 1060-1069. https://doi.org/10.1016/j.celrep.2013.10.030

Barry, R., John, S.W., Liccardi, G., Tenev, T., Jaco, I., Chen, C.-H., Choi, J., Kasperkiewicz, P., Fernandes-Alnemri, T., Alnemri, E., Drag, M., Chen, Y., Meier, P., 2018. SUMO-mediated regulation of NLRP3 modulates inflammasome activity. Nat Commun 9, 3001. https://doi.org/10.1038/s41467-018-05321-2

Bingol, B., Tea, J.S., Phu, L., Reichelt, M., Bakalarski, C.E., Song, Q., Foreman, O., Kirkpatrick, D.S., Sheng, M., 2014. The mitochondrial deubiquitinase USP30 opposes parkinmediated mitophagy. Nature 510, 370-375. https://doi.org/10.1038/nature13418

Bochkis, I.M., Rubins, N.E., White, P., Furth, E.E., Friedman, J.R., Kaestner, K.H., 2008. Hepatocyte-specific ablation of Foxa2 alters bile acid homeostasis and results in endoplasmic reticulum stress. Nat Med 14, 828-836. https://doi.org/10.1038/nm.1853

BonDurant, L.D., Potthoff, M.J., 2018. Fibroblast Growth Factor 21: A Versatile Regulator of Metabolic Homeostasis. Annu Rev Nutr 38, 173-196. https://doi.org/10.1146/annurevnutr-071816-064800

Bookout, A.L., de Groot, M.H.M., Owen, B.M., Lee, S., Gautron, L., Lawrence, H.L., Ding, X., Elmquist, J.K., Takahashi, J.S., Mangelsdorf, D.J., Kliewer, S.A., 2013. FGF21 regulates metabolism and circadian behavior by acting on the nervous system. Nat Med 19, 11471152. https://doi.org/10.1038/nm.3249

Bosma, P.J., Seppen, J., Goldhoorn, B., Bakker, C., Oude Elferink, R.P., Chowdhury, J.R., Chowdhury, N.R., Jansen, P.L., 1994. Bilirubin UDP-glucuronosyltransferase 1 is the only relevant bilirubin glucuronidating isoform in man. J Biol Chem 269, 17960-17964.

Braschi, E., Goyon, V., Zunino, R., Mohanty, A., Xu, L., McBride, H.M., 2010. Vps35 Mediates Vesicle Transport between the Mitochondria and Peroxisomes. Current Biology 20, 1310-1315. https://doi.org/10.1016/j.cub.2010.05.066

Braschi, E., Zunino, R., McBride, H.M., 2009. MAPL is a new mitochondrial SUMO E3 ligase that regulates mitochondrial fission. EMBO Rep 10, 748-754. https://doi.org/10.1038/embor.2009.86

Chen, M.M., Hale, C., Stanislaus, S., Xu, J., Véniant, M.M., 2018. FGF21 acts as a negative regulator of bile acid synthesis. J Endocrinol 237, 139-152. https://doi.org/10.1530/JOE17-0727

Chiang, J.Y.L., 2009. Bile acids: regulation of synthesis. J Lipid Res 50, 1955-1966. https://doi.org/10.1194/jlr.R900010-JLR200

Comartin, D., Gupta, G.D., Fussner, E., Coyaud, É., Hasegan, M., Archinti, M., Cheung, S.W.T., Pinchev, D., Lawo, S., Raught, B., Bazett-Jones, D.P., Lüders, J., Pelletier, L., 2013. CEP120 and SPICE1 cooperate with CPAP in centriole elongation. Curr Biol 23, 1360-1366. https://doi.org/10.1016/j.cub.2013.06.002 
Coyaud, E., Mis, M., Laurent, E.M.N., Dunham, W.H., Couzens, A.L., Robitaille, M., Gingras, A.-C., Angers, S., Raught, B., 2015. BiolD-based Identification of Skp Cullin F-box (SCF) $\beta$ TrCP1/2 E3 Ligase Substrates. Mol Cell Proteomics 14, 1781-1795. https://doi.org/10.1074/mcp.M114.045658

Cyphert, H.A., Ge, X., Kohan, A.B., Salati, L.M., Zhang, Y., Hillgartner, F.B., 2012. Activation of the farnesoid $X$ receptor induces hepatic expression and secretion of fibroblast growth factor 21. J Biol Chem 287, 25123-25138. https://doi.org/10.1074/jbc.M112.375907

de Boer, J.F., Bloks, V.W., Verkade, E., Heiner-Fokkema, M.R., Kuipers, F., 2018. New insights in the multiple roles of bile acids and their signaling pathways in metabolic control. Curr Opin Lipidol 29, 194-202. https://doi.org/10.1097/MOL.0000000000000508

Doiron, K., Goyon, V., Coyaud, E., Rajapakse, S., Raught, B., McBride, H.M., 2017. The dynamic interacting landscape of MAPL reveals essential functions for SUMOylation in innate immunity. Sci Rep 7, 107. https://doi.org/10.1038/s41598-017-00151-6

Donepudi, A.C., Boehme, S., Li, F., Chiang, J.Y.L., 2017. G-protein-coupled bile acid receptor plays a key role in bile acid metabolism and fasting-induced hepatic steatosis in mice. Hepatology 65, 813-827. https://doi.org/10.1002/hep.28707

Escobar-Henriques, M., Langer, T., 2014. Dynamic survey of mitochondria by ubiquitin. EMBO Reports 15, 231. https://doi.org/10.1002/embr.201338225

Ferdinandusse, S., Jimenez-Sanchez, G., Koster, J., Denis, S., Van Roermund, C.W., Silva-Zolezzi, I., Moser, A.B., Visser, W.F., Gulluoglu, M., Durmaz, O., Demirkol, M., Waterham, H.R., Gökcay, G., Wanders, R.J.A., Valle, D., 2015. A novel bile acid biosynthesis defect due to a deficiency of peroxisomal ABCD3. Hum Mol Genet 24, 361-370. https://doi.org/10.1093/hmg/ddu448

Flippo, K.H., Potthoff, M.J., 2021. Metabolic Messengers: FGF21. Nat Metab 3, 309-317. https://doi.org/10.1038/s42255-021-00354-2

Guimarães, C.P., Domingues, P., Aubourg, P., Fouquet, F., Pujol, A., Jimenez-Sanchez, G., SáMiranda, C., Azevedo, J.E., 2004. Mouse liver PMP70 and ALDP: homomeric interactions prevail in vivo. Biochim Biophys Acta 1689, 235-243. https://doi.org/10.1016/j.bbadis.2004.04.001

Han, J., Liu, Y., Wang, R., Yang, J., Ling, V., Borchers, C.H., 2015. Metabolic profiling of bile acids in human and mouse blood by LC-MS/MS in combination with phospholipid-depletion solid-phase extraction. Anal Chem 87, 1127-1136. https://doi.org/10.1021/ac503816u

He, J., Cheng, J., Wang, T., 2020. SUMOylation-Mediated Response to Mitochondrial Stress. IJMS 21, 5657. https://doi.org/10.3390/ijms21165657

Hecker, C.-M., Rabiller, M., Haglund, K., Bayer, P., Dikic, I., 2006. Specification of SUMO1- and SUMO2-interacting motifs. J Biol Chem 281, 16117-16127. https://doi.org/10.1074/jbc.M512757200

Hetz, C., 2012. The unfolded protein response: controlling cell fate decisions under ER stress and beyond. Nat Rev Mol Cell Biol 13, 89-102. https://doi.org/10.1038/nrm3270

Itoh, N., 2014. FGF21 as a Hepatokine, Adipokine, and Myokine in Metabolism and Diseases. Front Endocrinol (Lausanne) 5, 107. https://doi.org/10.3389/fendo.2014.00107

Jenkins, K., Khoo, J.J., Sadler, A., Piganis, R., Wang, D., Borg, N.A., Hjerrild, K., Gould, J., Thomas, B.J., Nagley, P., Hertzog, P.J., Mansell, A., 2013. Mitochondrially localised MUL1 is a 
821

822

823

824

825

826

827

828

829

830

831

832

833

834

835

836

837

838

839

840

841

842

843

844

845

846

847

848

849

850

851

852

853

854

855

856

857

858

859

860

861

862

863

novel modulator of antiviral signaling. Immunol Cell Biol 91, 321-330.

https://doi.org/10.1038/icb.2013.7

Jung, J.H., Bae, S., Lee, J.Y., Woo, S.R., Cha, H.J., Yoon, Y., Suh, K.-S., Lee, S.-J., Park, I.-C., Jin, Y.W., Lee, K.-H., An, S., Lee, J.H., 2011. E3 ubiquitin ligase Hades negatively regulates the exonuclear function of p53. Cell Death Differ 18, 1865-1875. https://doi.org/10.1038/cdd.2011.57

Köntgen, F., Süss, G., Stewart, C., Steinmetz, M., Bluethmann, H., 1993. Targeted disruption of the MHC class II Aa gene in C57BL/6 mice. Int Immunol 5, 957-964. https://doi.org/10.1093/intimm/5.8.957

Kraus, F., Ryan, M.T., 2017. The constriction and scission machineries involved in mitochondrial fission. J Cell Sci 130, 2953-2960. https://doi.org/10.1242/jcs.199562

Li, J., Qi, W., Chen, G., Feng, D., Liu, J., Ma, B., Zhou, C., Mu, C., Zhang, W., Chen, Q., Zhu, Y., 2015. Mitochondrial outer-membrane E3 ligase MUL1 ubiquitinates ULK1 and regulates selenite-induced mitophagy. Autophagy 11, 1216-1229. https://doi.org/10.1080/15548627.2015.1017180

Li, W., Bengtson, M.H., Ulbrich, A., Matsuda, A., Reddy, V.A., Orth, A., Chanda, S.K., Batalov, S., Joazeiro, C.A.P., 2008. Genome-wide and functional annotation of human E3 ubiquitin ligases identifies MULAN, a mitochondrial E3 that regulates the organelle's dynamics and signaling. PLoS One 3, e1487. https://doi.org/10.1371/journal.pone.0001487

Lorbek, G., Lewinska, M., Rozman, D., 2012. Cytochrome P450s in the synthesis of cholesterol and bile acids--from mouse models to human diseases. FEBS J 279, 1516-1533. https://doi.org/10.1111/j.1742-4658.2011.08432.x

Marcassa, E., Kallinos, A., Jardine, J., Rusilowicz-Jones, E.V., Martinez, A., Kuehl, S., Islinger, M., Clague, M.J., Urbé, S., 2018. Dual role of USP30 in controlling basal pexophagy and mitophagy. EMBO Rep 19, e45595. https://doi.org/10.15252/embr.201745595

Mohanty, A., Zunino, R., Soubannier, V., Dilipkumar, S., 2021. A new functional role of mitochondria-anchored protein ligase in peroxisome morphology in mammalian cells. J Cell Biochem 122, 1686-1700. https://doi.org/10.1002/jcb.30114

Neuspiel, M., Schauss, A.C., Braschi, E., Zunino, R., Rippstein, P., Rachubinski, R.A., AndradeNavarro, M.A., McBride, H.M., 2008. Cargo-selected transport from the mitochondria to peroxisomes is mediated by vesicular carriers. Curr Biol 18, 102-108. https://doi.org/10.1016/j.cub.2007.12.038

Ni, G., Konno, H., Barber, G.N., 2017. Ubiquitination of STING at lysine 224 controls IRF3 activation. Sci Immunol 2, eaah7119. https://doi.org/10.1126/sciimmunol.aah7119

Nunnari, J., Suomalainen, A., 2012. Mitochondria: in sickness and in health. Cell 148, 11451159. https://doi.org/10.1016/j.cell.2012.02.035

Owen, B.M., Ding, X., Morgan, D.A., Coate, K.C., Bookout, A.L., Rahmouni, K., Kliewer, S.A., Mangelsdorf, D.J., 2014. FGF21 acts centrally to induce sympathetic nerve activity, energy expenditure, and weight loss. Cell Metab 20, 670-677. https://doi.org/10.1016/j.cmet.2014.07.012

Pan, X., Shao, Y., Wu, F., Wang, Yuan, Xiong, R., Zheng, J., Tian, H., Wang, B., Wang, Yanfang, Zhang, Y., Han, Z., Qu, A., Xu, H., Lu, A., Yang, T., Li, X., Xu, A., Du, J., Lin, Z., 2018. FGF21 Prevents Angiotensin II-Induced Hypertension and Vascular Dysfunction by Activation of 
ACE2/Angiotensin-(1-7) Axis in Mice. Cell Metab 27, 1323-1337.e5. https://doi.org/10.1016/j.cmet.2018.04.002

Patel, R., Bookout, A.L., Magomedova, L., Owen, B.M., Consiglio, G.P., Shimizu, M., Zhang, Y., Mangelsdorf, D.J., Kliewer, S.A., Cummins, C.L., 2015. Glucocorticoids regulate the metabolic hormone FGF21 in a feed-forward loop. Mol Endocrinol 29, 213-223. https://doi.org/10.1210/me.2014-1259

Prudent, J., Zunino, R., Sugiura, A., Mattie, S., Shore, G.C., McBride, H.M., 2015. MAPL SUMOylation of Drp1 Stabilizes an ER/Mitochondrial Platform Required for Cell Death. Molecular Cell 59, 941-955. https://doi.org/10.1016/j.molcel.2015.08.001

Ranea-Robles, P., Chen, H., Stauffer, B., Yu, C., Bhattacharya, D., Friedman, S.L., Puchowicz, M., Houten, S.M., 2021. The peroxisomal transporter ABCD3 plays a major role in hepatic dicarboxylic fatty acid metabolism and lipid homeostasis. J Inherit Metab Dis. https://doi.org/10.1002/jimd.12440

Rojansky, R., Cha, M.-Y., Chan, D.C., 2016. Elimination of paternal mitochondria in mouse embryos occurs through autophagic degradation dependent on PARKIN and MUL1. Elife 5, e17896. https://doi.org/10.7554/eLife.17896

Roux, K.J., 2013. Marked by association: techniques for proximity-dependent labeling of proteins in eukaryotic cells. Cell Mol Life Sci 70, 3657-3664. https://doi.org/10.1007/s00018-013-1287-3

Roux, K.J., Kim, D.I., Raida, M., Burke, B., 2012. A promiscuous biotin ligase fusion protein identifies proximal and interacting proteins in mammalian cells. J Cell Biol 196, 801-810. https://doi.org/10.1083/jcb.201112098

Salminen, A., Kaarniranta, K., Kauppinen, A., 2017. Integrated stress response stimulates FGF21 expression: Systemic enhancer of longevity. Cell Signal 40, 10-21. https://doi.org/10.1016/j.cellsig.2017.08.009

Song, P., Zechner, C., Hernandez, G., Cánovas, J., Xie, Y., Sondhi, V., Wagner, M., Stadlbauer, V., Horvath, A., Leber, B., Hu, M.C., Moe, O.W., Mangelsdorf, D.J., Kliewer, S.A., 2018. The Hormone FGF21 Stimulates Water Drinking in Response to Ketogenic Diet and Alcohol. Cell Metab 27, 1338-1347.e4. https://doi.org/10.1016/j.cmet.2018.04.001

Sorrentino, G., Perino, A., Yildiz, E., El Alam, G., Bou Sleiman, M., Gioiello, A., Pellicciari, R., Schoonjans, K., 2020. Bile Acids Signal via TGR5 to Activate Intestinal Stem Cells and Epithelial Regeneration. Gastroenterology 159, 956-968.e8. https://doi.org/10.1053/j.gastro.2020.05.067

Stiles, A.R., McDonald, J.G., Bauman, D.R., Russell, D.W., 2009. CYP7B1: one cytochrome P450, two human genetic diseases, and multiple physiological functions. J Biol Chem 284, 28485-28489. https://doi.org/10.1074/jbc.R109.042168

Tait, S.W.G., Green, D.R., 2012. Mitochondria and cell signalling. Journal of Cell Science 125, 807-815. https://doi.org/10.1242/jcs.099234

Tan, J.X., Finkel, T., 2020. Mitochondria as intracellular signaling platforms in health and disease. Journal of Cell Biology 219, e202002179. https://doi.org/10.1083/jcb.202002179

van Roermund, C.W.T., Ijlst, L., Wagemans, T., Wanders, R.J.A., Waterham, H.R., 2014. A role for the human peroxisomal half-transporter $A B C D 3$ in the oxidation of dicarboxylic acids. Biochim Biophys Acta 1841, 563-568. https://doi.org/10.1016/j.bbalip.2013.12.001 
Veniant, M.M., Sivits, G., Helmering, J., Komorowski, R., Lee, J., Fan, W., Moyer, C., Lloyd, D.J., 2015. Pharmacologic Effects of FGF21 Are Independent of the "Browning" of White Adipose Tissue. Cell Metab 21, 731-738. https://doi.org/10.1016/j.cmet.2015.04.019

Wagner, M., Halilbasic, E., Marschall, H.-U., Zollner, G., Fickert, P., Langner, C., Zatloukal, K., Denk, H., Trauner, M., 2005. CAR and PXR agonists stimulate hepatic bile acid and bilirubin detoxification and elimination pathways in mice. Hepatology 42, 420-430. https://doi.org/10.1002/hep.20784

Wanders, R.J.A., 2013. Peroxisomes in human health and disease: metabolic pathways, metabolite transport, interplay with other organelles and signal transduction. Subcell Biochem 69, 23-44. https://doi.org/10.1007/978-94-007-6889-5_2

Wang, Y., Yutuc, E., Griffiths, W.J., 2021. Cholesterol metabolism pathways - are the intermediates more important than the products? FEBS J 288, 3727-3745. https://doi.org/10.1111/febs.15727

Worthmann, A., John, C., Rühlemann, M.C., Baguhl, M., Heinsen, F.-A., Schaltenberg, N., Heine, M., Schlein, C., Evangelakos, I., Mineo, C., Fischer, M., Dandri, M., Kremoser, C., Scheja, L., Franke, A., Shaul, P.W., Heeren, J., 2017. Cold-induced conversion of cholesterol to bile acids in mice shapes the gut microbiome and promotes adaptive thermogenesis. Nat Med 23, 839-849. https://doi.org/10.1038/nm.4357

Yun, J., Puri, R., Yang, H., Lizzio, M.A., Wu, C., Sheng, Z.-H., Guo, M., 2014. MUL1 acts in parallel to the PINK1/parkin pathway in regulating mitofusin and compensates for loss of PINK1/parkin. Elife 3, e01958. https://doi.org/10.7554/eLife.01958

Zhang, B., Huang, J., Li, H.-L., Liu, T., Wang, Y.-Y., Waterman, P., Mao, A.-P., Xu, L.-G., Zhai, Z., Liu, D., Marrack, P., Shu, H.-B., 2008. GIDE is a mitochondrial E3 ubiquitin ligase that induces apoptosis and slows growth. Cell Res 18, 900-910. https://doi.org/10.1038/cr.2008.75

Zhang, Y., Xie, Y., Berglund, E.D., Coate, K.C., He, T.T., Katafuchi, T., Xiao, G., Potthoff, M.J., Wei, W., Wan, Y., Yu, R.T., Evans, R.M., Kliewer, S.A., Mangelsdorf, D.J., 2012. The starvation hormone, fibroblast growth factor-21, extends lifespan in mice. Elife 1, e00065. https://doi.org/10.7554/eLife.00065 
bioRxiv preprint doi: https://doi.org/10.1101/2022.03.03.482848; this version posted March 4, 2022. The copyright holder for this preprint (which was not certified by peer review) is the author/funder, who has granted bioRxiv a license to display the preprint in perpetuity. It is made available under aCC-BY 4.0 International license.

\section{Goyon et al., Figure 1}

\begin{tabular}{|c|c|c|c|}
\hline $\begin{array}{c}\text { Protein } \\
\text { name }\end{array}$ & Function & \begin{tabular}{|l|} 
SAINT score \\
(no MG132)
\end{tabular} & $\begin{array}{l}\text { SAINT score } \\
(+ \text { MG132) } \\
\end{array}$ \\
\hline $\mathrm{ABCD} 3$ & peroxisomal import of fatty acids & 1537 & 973 \\
\hline AKAP1 & mitochondrial fission & 612 & 544 \\
\hline DNM1L (DRP1) & mitochondrial fission & 565 & 729 \\
\hline MAVS & immunity & 379 & 263 \\
\hline IFN2 & mitochondrial fission & 189 & 161 \\
\hline MFF & mitochondrial fission & 167 & 136 \\
\hline USP30 & mitochondrial fission & 153 & 128 \\
\hline PRKAR2A & mitochondrial fission & 61 & 47 \\
\hline
\end{tabular}
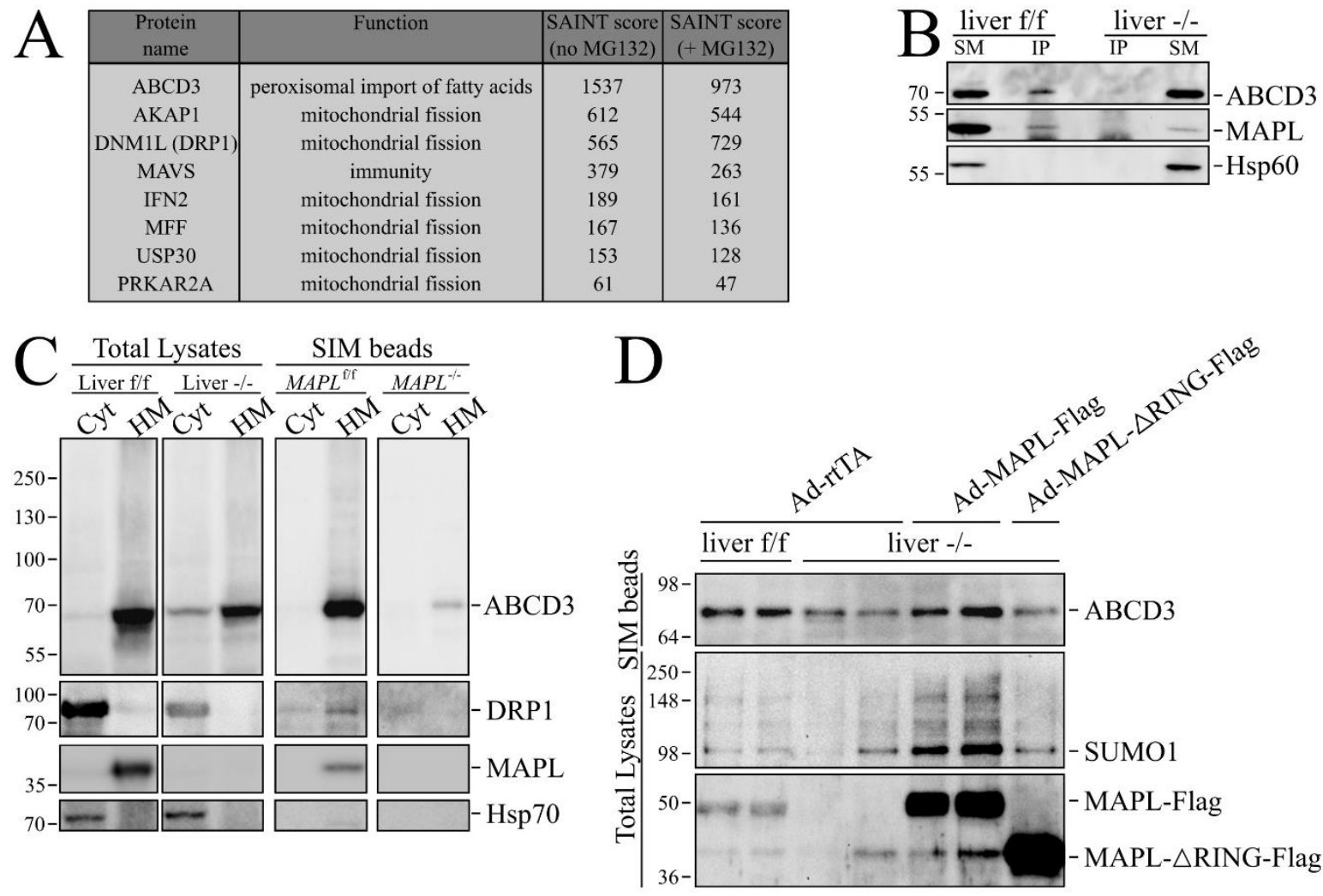

$\mathrm{E}$
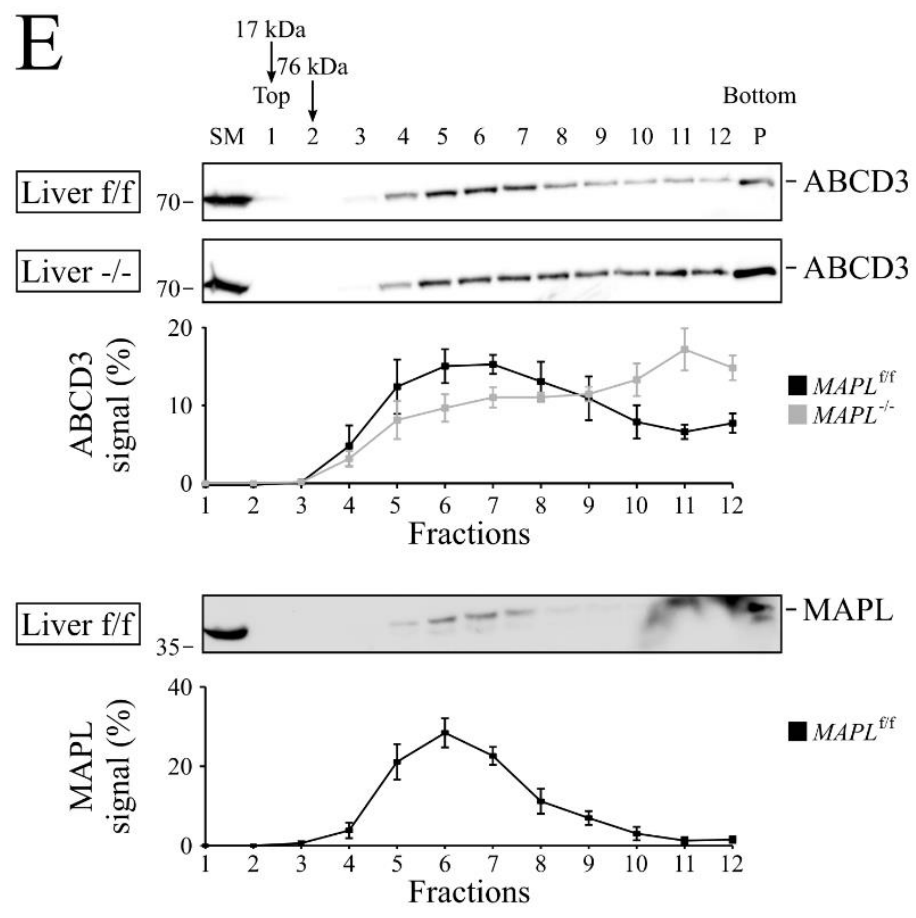

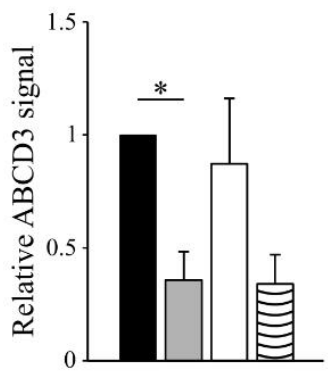

$M A P L^{\mathrm{f} / \mathrm{f}}+\mathrm{Ad}-\mathrm{rtTA}$

$\square M A P L^{-/-}+$Ad-rtTA

$\square M A P L^{-/}+$Ad-MAPL-Flag

曰MAPL $L^{-/}+$Ad-MAPL- $\triangle$ RING-Flag 


\section{Figure 1: MAPL SUMOylates ABCD3 and modulates complex assembly.}

943 A. HEK293T-REX (tetracyline-regulatable expression) cells stably expressing an inducible Tet-ON 944 fusion construct MAPL-Flag-BirA or Flag-BirA were induced for 24 hours in the presence of 945 biotin, and biotinylated proteins were isolated with streptavidin beads for identification by 946 mass spectrometry. The top hits by peptide counts are shown.

947 B. Starting materials (SM) and MAPL immunoprecipitated (IP) fractions obtained from liver 948 crude extracts were probed for ABCD3, MAPL and Hsp60.

949 C. Cytosol and heavy membrane fractions isolated from $\mathrm{MAPL}^{\mathrm{f} / \mathrm{f}}$ and $\mathrm{MAPL}^{-/-}$livers were 950 solubilized and incubated with SIM beads, and elution fractions probed for ABCD3, DRP1, Hsp70 951 and MAPL (Cyt=cytosolic fraction, $\mathrm{HM}=$ heavy membrane fraction).

952 D. Heavy membrane fractions isolated from livers of $\mathrm{MAPL}^{\mathrm{f} / \mathrm{f}}$ and $\mathrm{MAPL}^{-/-}$animals tail-vein 953 injected with adenovirus expressing MAPL-Flag, MAPL- $\triangle$ RING-Flag or empty virus (Ad-rtTA)

954 were solubilized and incubated with SIM beads. Elution fractions were probed for ABCD3, 955 SUMO1 and MAPL (top panel). Quantification from 3 independent experiments of ABCD3 956 signals of the heavy membrane SIM-beads elution fraction from livers isolated from rescued 957 mice (lower panel).

958 E. $250 \mu \mathrm{g}$ of solubilized protein (from $\mathrm{MAPL}^{\mathrm{f} / \mathrm{f}}$ and $\mathrm{MAPL}^{-/-}$livers) were separated on a 10-50\% $959(\mathrm{w} / \mathrm{v})$ sucrose gradient. 12 different fractions, as well as the resuspended pellet $(P)$ were 960 analyzed by western blot. ABCD3 signals from $\mathrm{MAPL}^{\mathrm{f} / \mathrm{f}}$ and $\mathrm{MAPL}^{-/-}$livers in the different 961 fractions were quantified and plotted as percentage of the total signal, from 3 biological 962 replicates.

$963 * P<0.05$ in a one-way ANOVA 
bioRxiv preprint doi: https://doi.org/10.1101/2022.03.03.482848; this version posted March 4.2022. The copyright holder for this preprint (which was not certified by peer review) is the author/funder, who has granted bioRxiv a license to display the preprint in perpetuity. It is made available under aCC-BY 4.0 International license.
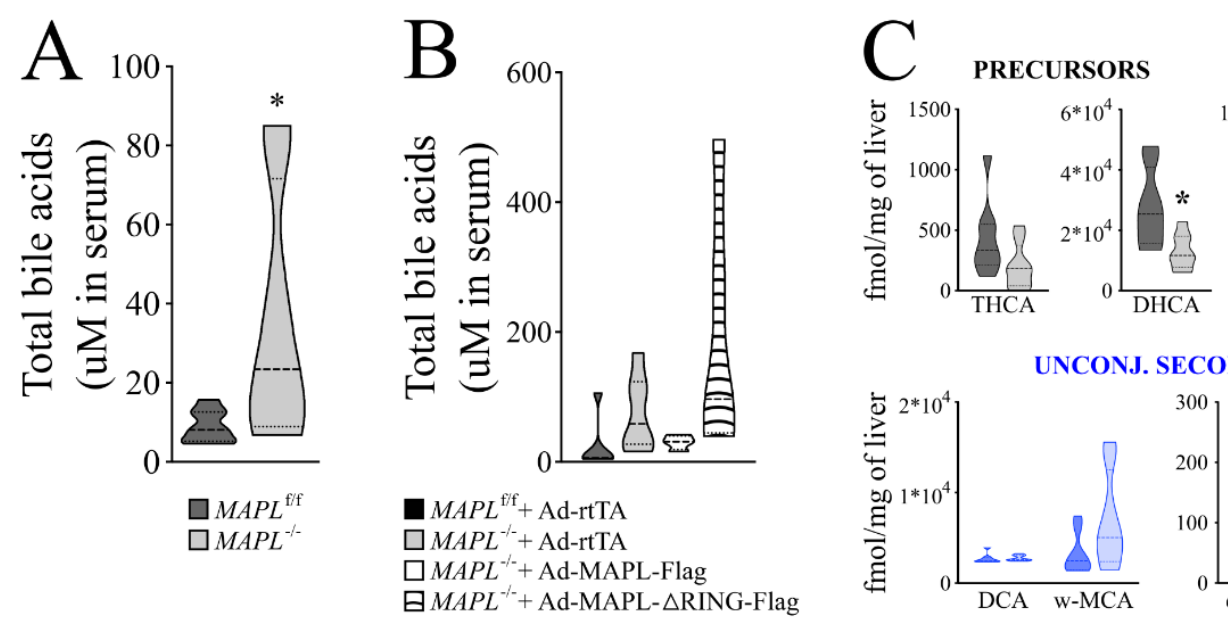

Goyon et al., Figure 2

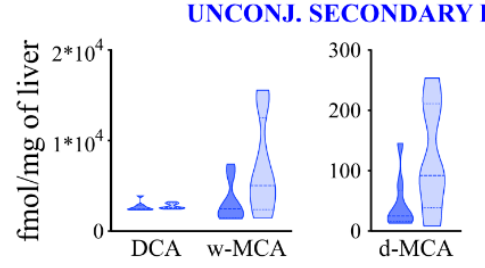

UNCONJ. PRIMARY BA

$\mathrm{D}$

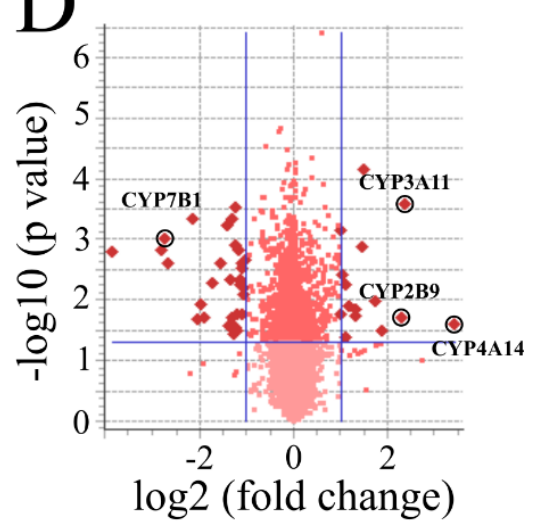

TAURO-CONJ. SECONDARY BA

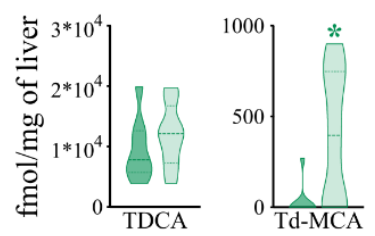

$\mathrm{F}$

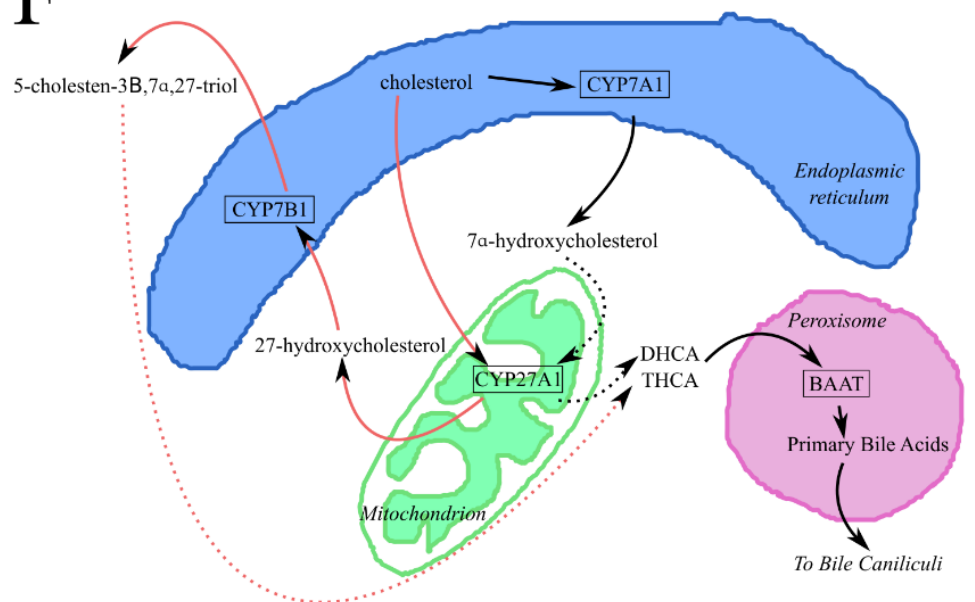

$\mathrm{E}$

\begin{tabular}{|l|c|c|c|}
\hline \multicolumn{1}{|c|}{ Target ID } & Gene ID & $\begin{array}{c}\text { Fold } \\
\text { change }\end{array}$ & p-value \\
\hline HSD3B5/Hsd1 & 15496 & $\mathbf{- 1 4 . 2 8}$ & 0.00165 \\
\hline CYP7B1 & 13123 & $\mathbf{- 6 . 5 8}$ & 0.00097 \\
\hline ELOVL3 & 12686 & $\mathbf{- 6 . 2 2}$ & 0.00246 \\
\hline CYP2D9 & 13105 & $\mathbf{- 2 . 2 2}$ & 0.00153 \\
\hline DCT & 13190 & $\mathbf{- 2 . 4 6}$ & 0.00047 \\
\hline UGT3A1 & 105887 & $\mathbf{- 2 . 1 5}$ & 0.00545 \\
\hline CYP4A11 & & $\mathbf{2 . 2 7}$ & 0.08251 \\
\hline UGT1A12 & 394434 & $\mathbf{2 . 7 5}$ & 0.00129 \\
\hline CYP3A11 & 13112 & $\mathbf{4 . 8 7}$ & 0.02011 \\
\hline CYP2B9 & 13094 & $\mathbf{5 . 1 6}$ & 0.00026 \\
\hline CYP4A14 & 13119 & $\mathbf{1 0 . 6 7}$ & 0.02532 \\
\hline
\end{tabular}

G $\frac{\text { Liver } 1 \text { Liver } 2 \text { Liver } 3}{\mathrm{f} / \mathrm{f}-/-}$

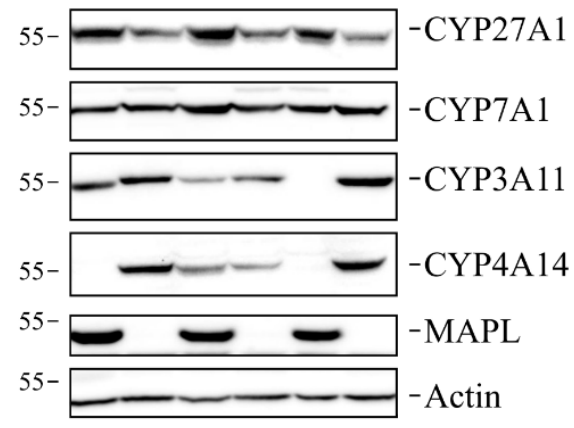


Figure 2: MAPL represses bile acid synthesis.

987 A. Total bile acids within the serum was quantified as described in material and methods ( $n=8$ 988 for each strain, 6 females and 2 males, 2-6 month old).

989 B. Total bile acids within the serum of tail vein injected animals was quantified as described in material and methods ( $n=6$ with 4 females and 2 males, $n=7$ with 4 females and 3 males, $n=4$ 991 with 2 females and 2 males and $n=5$ with 2 females and 3 males, for MAPL ${ }^{\mathrm{f} / \mathrm{f}}+\mathrm{rtTA}, \mathrm{MAPL}^{-/-}+$ 992 rtTA, MAPL ${ }^{--}+$MAPL-Flag and MAPL ${ }^{-/}+$MAPL- $\triangle$ RING-Flag, respectively, 2-3 month old).

993 C. Bile acids precursors, as well as unconjugated and conjugated primary and secondary bile 994 acids were quantified from liver ( $n=8$ for each strain, 2 month old males). THCA and DHCA: tri995 and dihydroxycholestanoic acid; CA: cholic acid; a-MCA, b-MCA, w-MCA and d-MCA: $\alpha-, \beta-, \gamma^{-}$ 996 and $\delta$-muricholic acid; DCA: deoxycholic acid; MCA: murocholic acid; HDCA: hyodeoxycholic 997 acid; TDCA: taurodeoxycholic acid; td-MCA: tauro- $\delta$-muricholic acid.

998 D. Volcano plot representation of the Illumina analysis performed on 5-month males $(n=3$, each 999 strain, in triplicate). Circles highlight the significant changes in bile acid related enzymes.

1000 E. Table resulting from the Illumina analysis (in D) highlighting genes with variations higher than 10012 -fold (with a p-value <0.05, calculated with unpaired two-tailed students t-test) implicated in 1002 steroid and bile acid metabolism.

1003 F. A model depicting the required flux of metabolites between the ER, mitochondria and 1004 peroxisomes to facilitate bile acid synthesis in the liver. The classical pathway is represented 1005 with black arrows, while the alternative pathway is represented with red arrows.

1006 G. Transcriptome results were validated with western blots from whole cell liver extracts from 3 1007 animals of each strain (one female, two males), as indicated.

$1008 * P<0.05 * * P<0.01$ in an unpaired two-tailed $T$ test 
bioRxiv preprint doi: https://doi.org/10.1101/2022.03.03.482848; this version posted March 4 2022. The copyright holder for this preprint (which was not certified by peer review) is the author/funder, who has granted bioRxiv a license to display the preprint in perpetuity. It is made available under aCC-BY 4.0 International license.

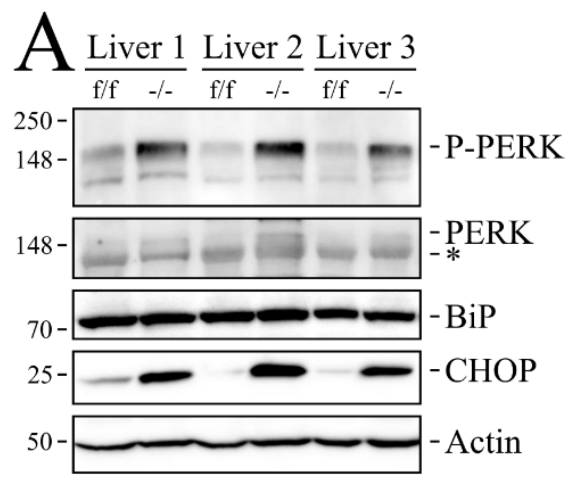

D $\frac{\text { Liver } 1}{\mathrm{f} / \mathrm{f}-/-} \frac{\text { Liver } 2}{\mathrm{f} / \mathrm{f} \quad-/-} \frac{\text { Liver } 3}{\mathrm{f} / \mathrm{f} \quad-/-}$

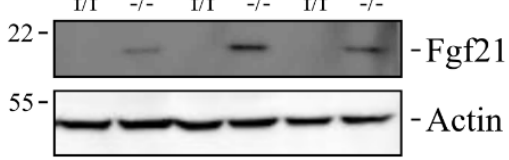

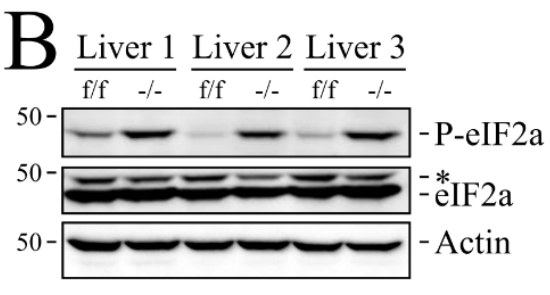

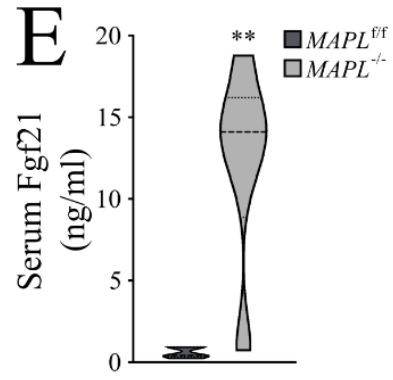

Goyon et al, Figure 3
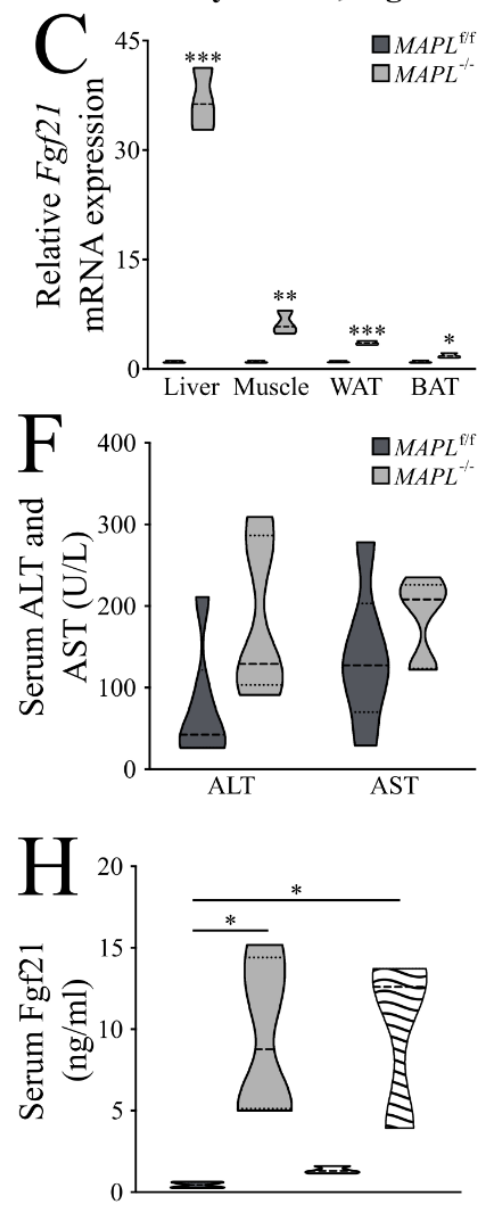

$\square M A P L^{\mathrm{f} / \mathrm{f}}+\mathrm{Ad}-\mathrm{rtTA}$

$\square M A P L+$ Ad-rtTA

$\square M A P L^{-/ \alpha}+$ Ad-MAPL-Flag

$\square M A P L^{-\alpha}+$ Ad-MAPL- $\triangle$ RING-Flag

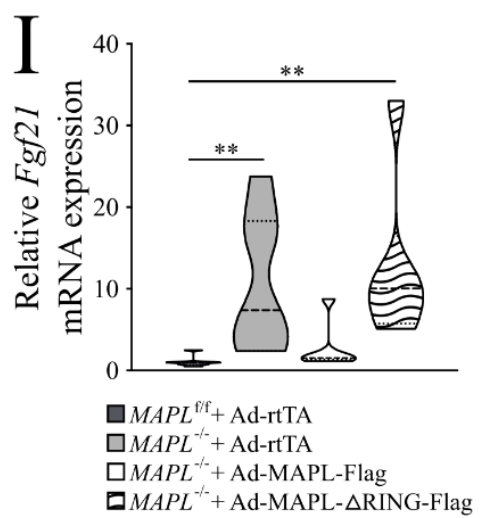

1010

1011

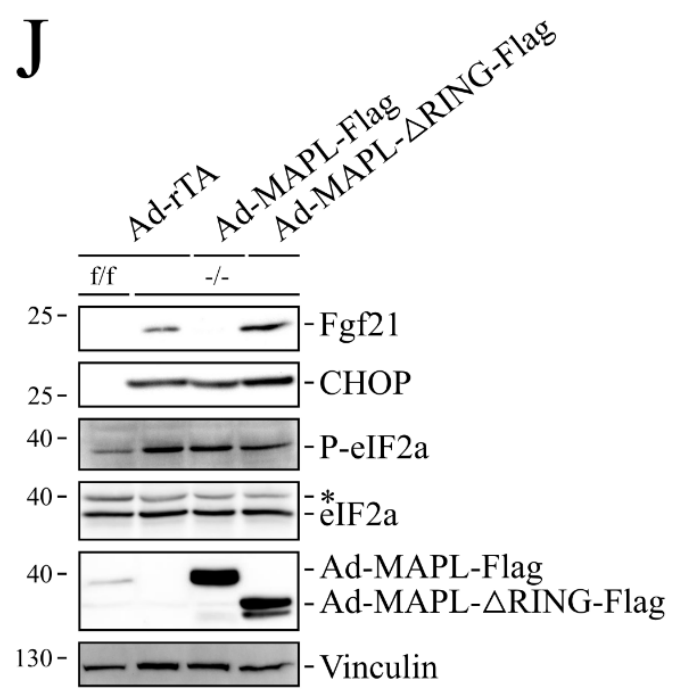


Figure 3: Loss of MAPL leads to hepatic ER stress, elF2 $\alpha$ activation and Fgf21 expression.

1014 A. Representative western blots from liver extracts from 3 animals of each strain: PERK autophosphorylation along with the total protein, as well as BIP and CHOP expression are shown $\left(^{*}\right.$ :

1016 unspecific signal).

1017 B. Representative western blots of elF2 $\alpha$ phosphorylation in liver extracts $(n=3)$.

1018

C. Fgf 21 mRNA expression measured by qRT-PCR performed on 4 different mouse tissues

1019 isolated from $\mathrm{MAPL}^{\mathrm{f} / \mathrm{f}}$ and $\mathrm{MAPL}^{-/-}$animals.

1020

D. Representative western-blots of increased FGF21 protein levels in liver from 3 pairs of mice

1021 from each strain (left panel).

1022 E. Serum FGF21 was quantified by ELISA ( $n=8$ for each strain, 2 month old males).

1023 F. Levels of alanine transaminase (ALT) and aspartate transaminase (AST) $(n=6,6$ month old 1024 males).

1025 G. Representative western blots from different tissues whole cell extracts from 1 male of each strain: PERK auto-phosphorylation, as well as BIP and CHOP expression are shown (Sto:

1027 stomach, *: remaining beta actin signal).

1028 H. Serum FGF21 was quantified by ELISA from tail vein injected adenoviral rescued mice $(n=4$ with 2 females and 2 males, $n=4$ with 2 females and 2 males, $n=3$ with 3 females and $n=3$ with 1 female and 2 males, for $\mathrm{MAPL}^{\mathrm{f} / \mathrm{f}}+\mathrm{rtTA}, \mathrm{MAPL}^{-/}+\mathrm{rtTA}^{\mathrm{MAPL}} \mathrm{MA}^{-/}+\mathrm{MAPL}-\mathrm{Flag}$ and $\mathrm{MAPL}^{-/-}+$ MAPL- $\triangle$ RING-Flag, respectively, 2-3 month old) I. Liver Fgf21 gene expression by qRT-PCR on livers of rescued mice (in triplicate, $n=7$ with 4 females and 3 males, $n=7$ with 4 females and 3 males, $n=5$ with 3 females and 2 males and $n=6$ with 3 females and 3 males, for MAPL f/f + rtTA, MAPL ${ }^{-1-}+$ rtTA, MAPL ${ }^{-1-}+\mathrm{MAPL}^{-F l a g}$ and MAPL $\mathrm{MA}^{-/}$ + MAPL- $\triangle$ RING-Flag, respectively, 2-3 month old, right panel)

J. Representative western-blot from rescued liver extracts probed for Fgf21, CHOP, P-elF2 $\alpha$ and 1037 elF2 $\alpha$ as indicated.

$* P<0.05 * * P<0.01 * * * P<0.001$ using T test for two group comparison and multiple

1039 comparison correction (C,E) or ANOVA for multiple group comparisons $(\mathbf{H}, \mathbf{I})$ 

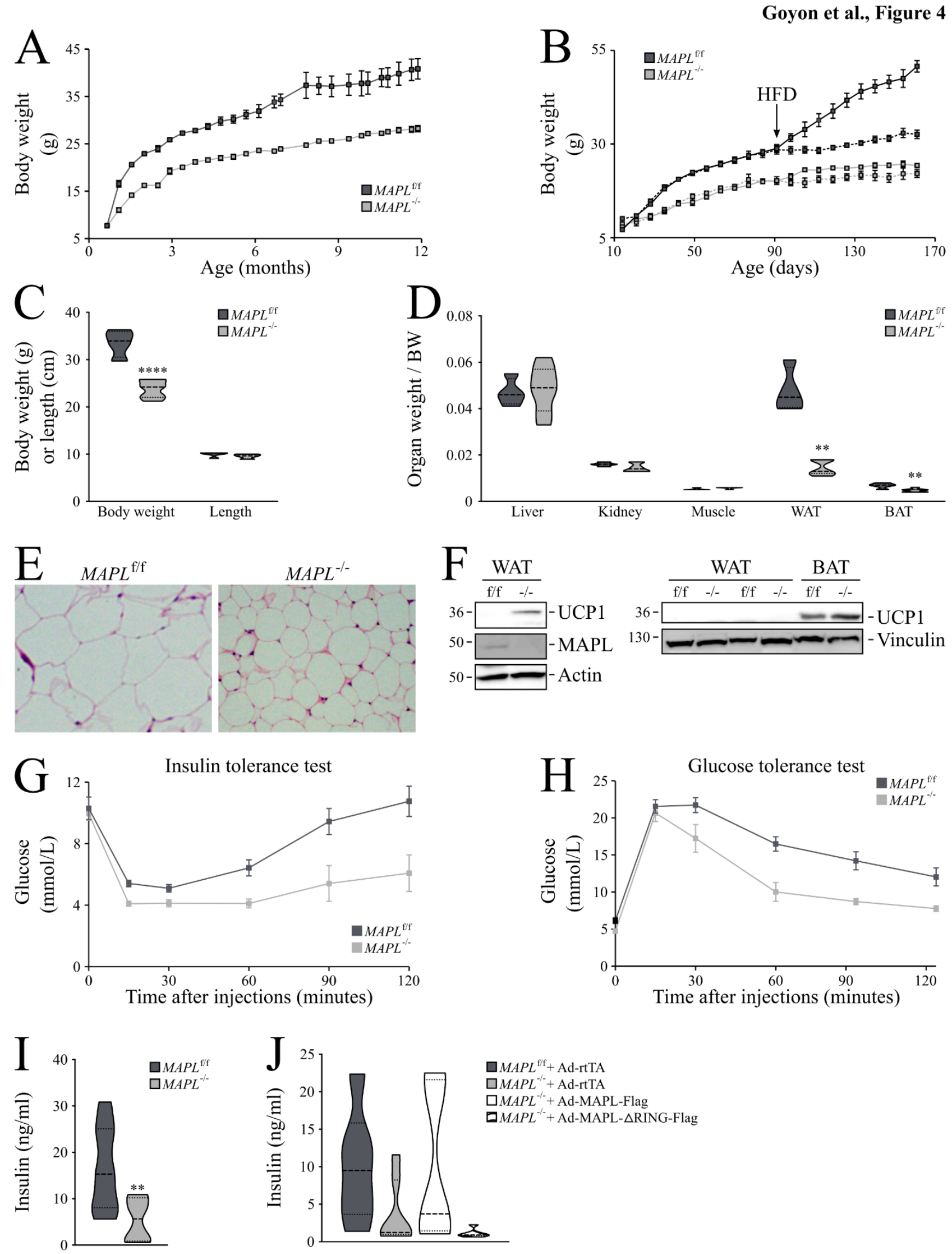
Figure 4: $M A P L^{-/-}$mice are lean and have increased glucose tolerance.

1045 A. Body weight (g) of male mice fed with normal chow; $\mathrm{MAPL}^{\mathrm{f} / \mathrm{f}}(\mathrm{n}=6)$, and $\mathrm{MAPL}^{-/-}(\mathrm{n}=9)$.

1046 B. Body weight $(g)$ of $\mathrm{MAPL}^{\mathrm{f} / \mathrm{f}}(\mathrm{n}=8)$ and $\mathrm{MAPL}^{--}(\mathrm{n}=7)$ male mice. They were fed normal chow

1047 for 5 months (dotted lines), or for 3 months followed by 2 months of a $60 \%$ fat diet (solid lines, 1048 diet change indicated by HFD arrow).

1049 C. Body weight ( $\mathrm{g}$, left panel) or length (cm, right panel) of 7-month-old MAPL ${ }^{\mathrm{f} / \mathrm{f}}(\mathrm{n}=4)$ or $\mathrm{MAPL}^{-/-}$ $1050 \quad(n=7)$ male mice.

1051 D. Wet weight of organs including liver, kidney, gastrocnemius muscle, epididymal white fat 1052 (WAT) and interscapular brown fat (BAT) isolated from 7-month-old male $\mathrm{MAPL}^{\mathrm{f} / \mathrm{f}}(\mathrm{n}=4)$ or $1053 \mathrm{MAPL}^{-/-}(\mathrm{n}=7)$ mice.

1054 E. Representative pictures of white adipocytes from $\mathrm{MAPL}^{\mathrm{f} / \mathrm{f}}$ and $\mathrm{MAPL}^{-/-}$mice. Hematoxylin and 1055 eosin staining, 40X objective.

1056 F. Representative western-blots of Ucp1 from WAT and BAT whole cell extracts from 3 different 1057 pairs of mice $(n=3)$.

1058 G. Insulin tolerance test in male $\mathrm{MAPL}^{\mathrm{f} / \mathrm{f}}(\mathrm{n}=7)$ and $\mathrm{MAPL}^{-/-}(\mathrm{n}=7)$ mice. Insulin $(0.5 \mathrm{U} / \mathrm{kg})$ was 1059 injected intraperitoneally following a $4 \mathrm{~h}$ fast and blood glucose was measured at indicated 1060 times.

1061 H. Glucose tolerance test in male $\mathrm{MAPL}^{\mathrm{f} / \mathrm{f}}(\mathrm{n}=8)$ and $\mathrm{MAPL}^{-/-}(\mathrm{n}=8)$ mice. Glucose $(2 \mathrm{~g} / \mathrm{kg})$ was 1062 injected intraperitoneally following an overnight fast and blood glucose was measured at 1063 indicated times.

1064 I. Insulinemia $(\mathrm{ng} / \mathrm{mL})$ measured by ELISA in $\mathrm{MAPL}^{\mathrm{f} / \mathrm{f}}(\mathrm{n}=8)$ and $\mathrm{MAPL}^{-/-}(\mathrm{n}=8)$ male mice 1065 J. Insulinemia $(\mathrm{ng} / \mathrm{mL})$ measured by ELISA from tail vein injected adenoviral rescued mice $(\mathrm{n}=4$ 1066 with 2 females and 2 males, $n=4$ with 2 females and 2 males, $n=3$ with 3 females and $n=3$ with 1 1067 female and 2 males, for $\mathrm{MAPL}^{\mathrm{f} / \mathrm{f}}+\mathrm{rtTA}^{\mathrm{MAPL}} \mathrm{MA}^{-/}+\mathrm{rtTA}, \mathrm{MAPL}^{-/-}+\mathrm{MAPL}^{-F l a g}$ and $\mathrm{MAPL}^{-/-}+$ 1068 MAPL- $\triangle$ RING-Flag, respectively, 2-3-month-old). $* \mathrm{P}<0.05 * * \mathrm{P}<0.01 * * * \mathrm{P}<0.001 * * * * \mathrm{P}<0.0001$ using a repeated measures two way ANOVA and post hoc test $(\mathbf{G}, \mathbf{H}, \mathbf{I})$, unpaired $T$ test for two group comparison $(\mathbf{C}, \mathbf{D}, \mathbf{J})$ 
bioRxiv preprint doi: https://doi.org/10.1101/2022.03.03.482848; this version posted March 4, 2022. The copyright holder for this preprint (which was not certified by peer review) is the author/funder, who has granted bioRxiv a license to display the preprint in perpetuity. It is made available under aCC-BY 4.0 International license.
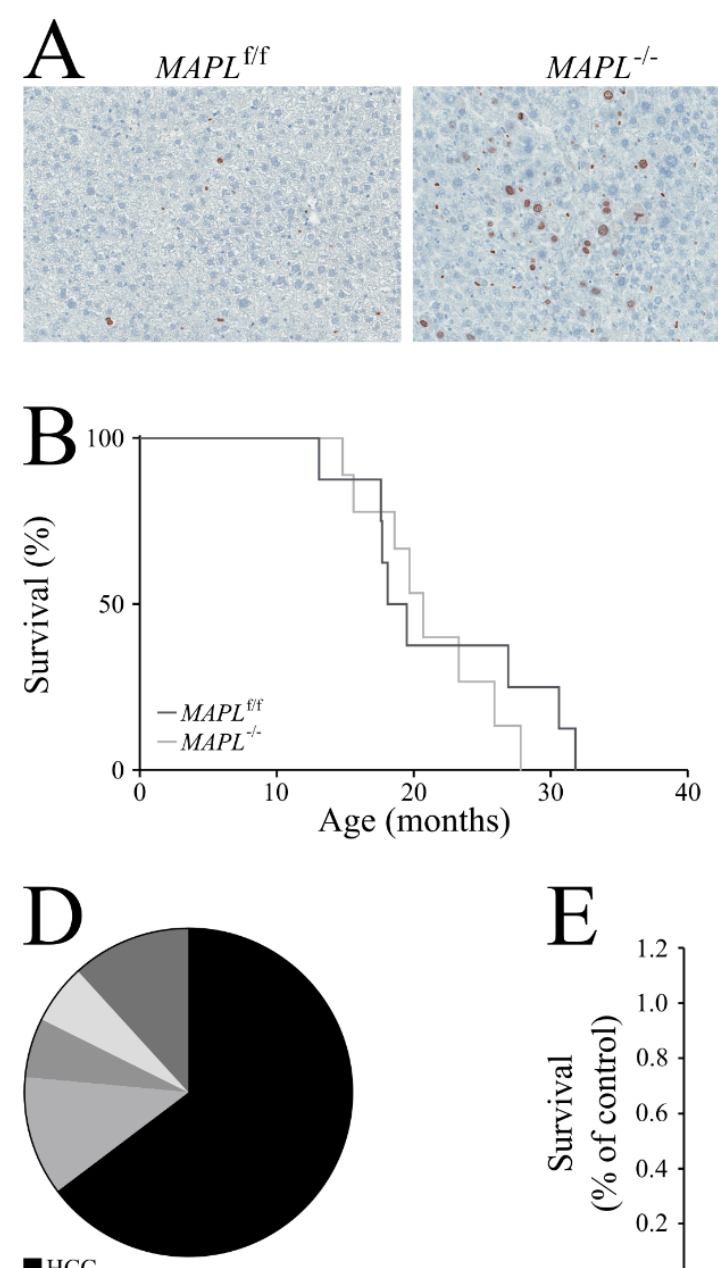

$\square \mathrm{HCC}$ with telangiectasia and endothelial atypia $\square \mathrm{HCC}$ with stem cell features, telangiectasia and endothelial atypia

$\square \mathrm{HCC}$ with stem cell features

$\square$ Combined HCC and cholangiocarcinoma
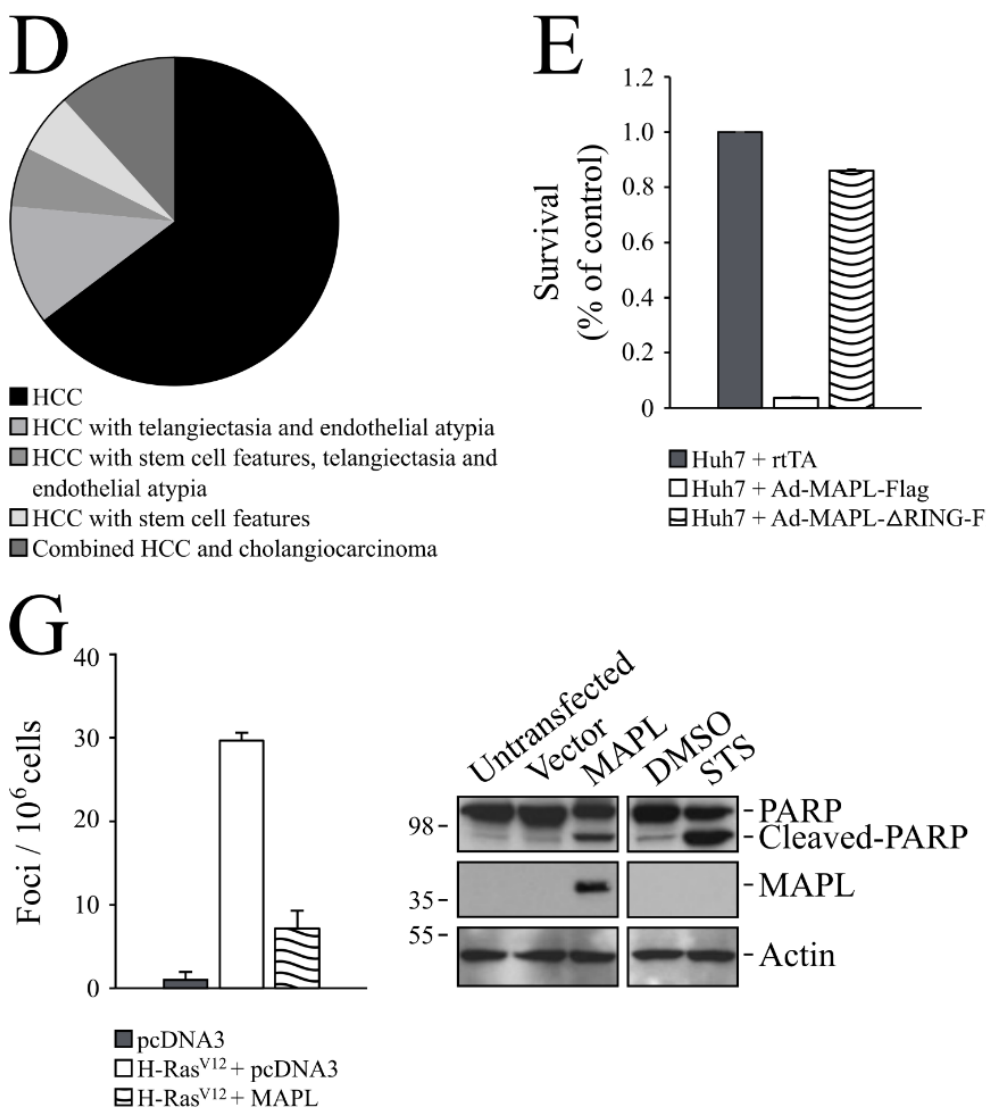

Figure 5. MAPL has tumor suppressive capability.
Goyon et al., Figure 5
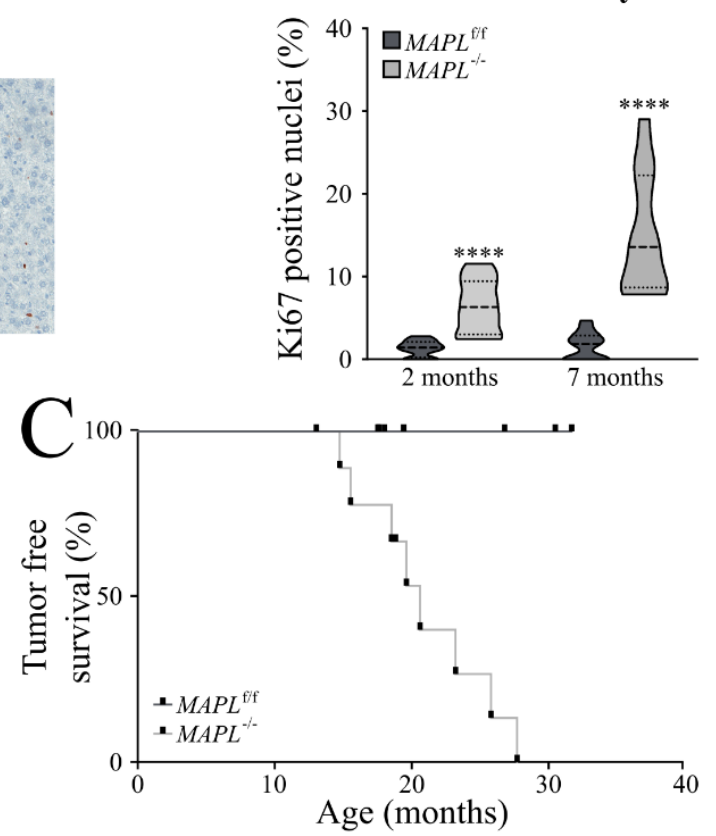

F

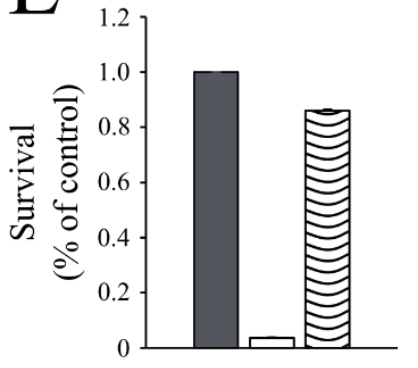

$\square \mathrm{Huh} 7+\mathrm{rtTA}$

$\square$ Huh7 + Ad-MAPL-Flag

日Huh7 + Ad-MAPL- $\triangle$ RING-Flag

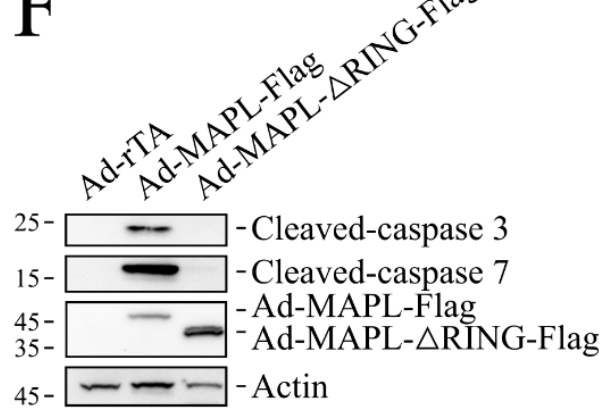

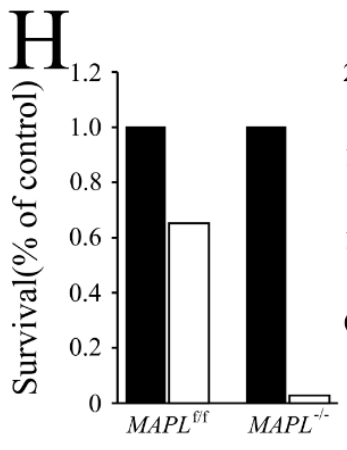

rtTA

$\square \mathrm{t}-\mathrm{BID}$

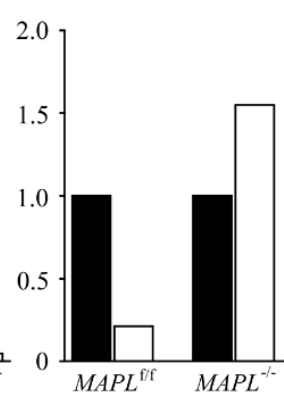

口rtTA

$\square$ Camptothecin 
1077 A. Representative pictures of Ki67 liver staining (left panel) and its quantification (right panel) in $1078 \mathrm{MAPL}^{\mathrm{f} / \mathrm{f}}$ and $\mathrm{MAPL}^{-/-}$mice.

1079 B. Survival curve of $\mathrm{MAPL}^{\mathrm{f} / \mathrm{f}}(\mathrm{N}=8)$ and $\mathrm{MAPL}^{-/-}(\mathrm{N}=9)$ mice

1080 C. Cancer free survival curve of $\mathrm{MAPL}^{\mathrm{f} / \mathrm{f}}\left(\mathrm{N}=8\right.$ and $\mathrm{MAPL}^{-/-}(\mathrm{N}=9)$ male mice.

1081 D. Pathological analysis of liver tumors in $\mathrm{MAPL}^{\mathrm{f} / \mathrm{f}}$ and $\mathrm{MAPL}^{-/-}$mice.

1082 E. Survival of Huh7 cells infected with adenoviruses expressing rTta, MAPL-flag, or MAPL-

$1083 \Delta$ RING-flag constructs.

1084 F. Immunoblots of cleaved caspase 3 and 7 from Huh7 cells infected with adenoviruses

1085 expressing rTta, MAPL-flag, or MAPL- $\triangle$ RING-flag constructs

1086 G. Ras foci in Rat2 fibroblasts cells transfected with empty pcDNA3 or overexpressing MAPL

1087 plasmids (left panel). Immunoblots of PARP, MAPL and beta-actin in Rat2 fibroblasts

1088 transfected with empty pcDNA3 or overexpressing MAPL plasmids (left panel). Immunoblots of 1089 PARP, MAPL and beta-actin in Rat2 fibroblasts treated with DMSO or Staurosporine (STS, $1 \mu$, $10903 \mathrm{~h}$ ).

1091 H. Survival of MAPL ${ }^{f / f}$ and MAPL $/-$ primary hepatocytes infected with adenoviruses expressing 1092 rTta or truncated BID (tBID) (left panel). Survival of MAPL ${ }^{\mathrm{f} / \mathrm{f}}$ and MAPL ${ }^{-/}$primary hepatocytes 1093 treated with camptothecin $(1 \mu \mathrm{M}, 15 \mathrm{~h})$ or vehicle.

$1094 * \mathrm{P}<0.05 * * \mathrm{P}<0.01 * * * \mathrm{P}<0.001$ using $\mathrm{T}$ test for two group comparison and multiple 1095 comparison correction $(\mathbf{A})$ or ANOVA for multiple group comparisons $(\mathbf{E}, \mathbf{G})$ 

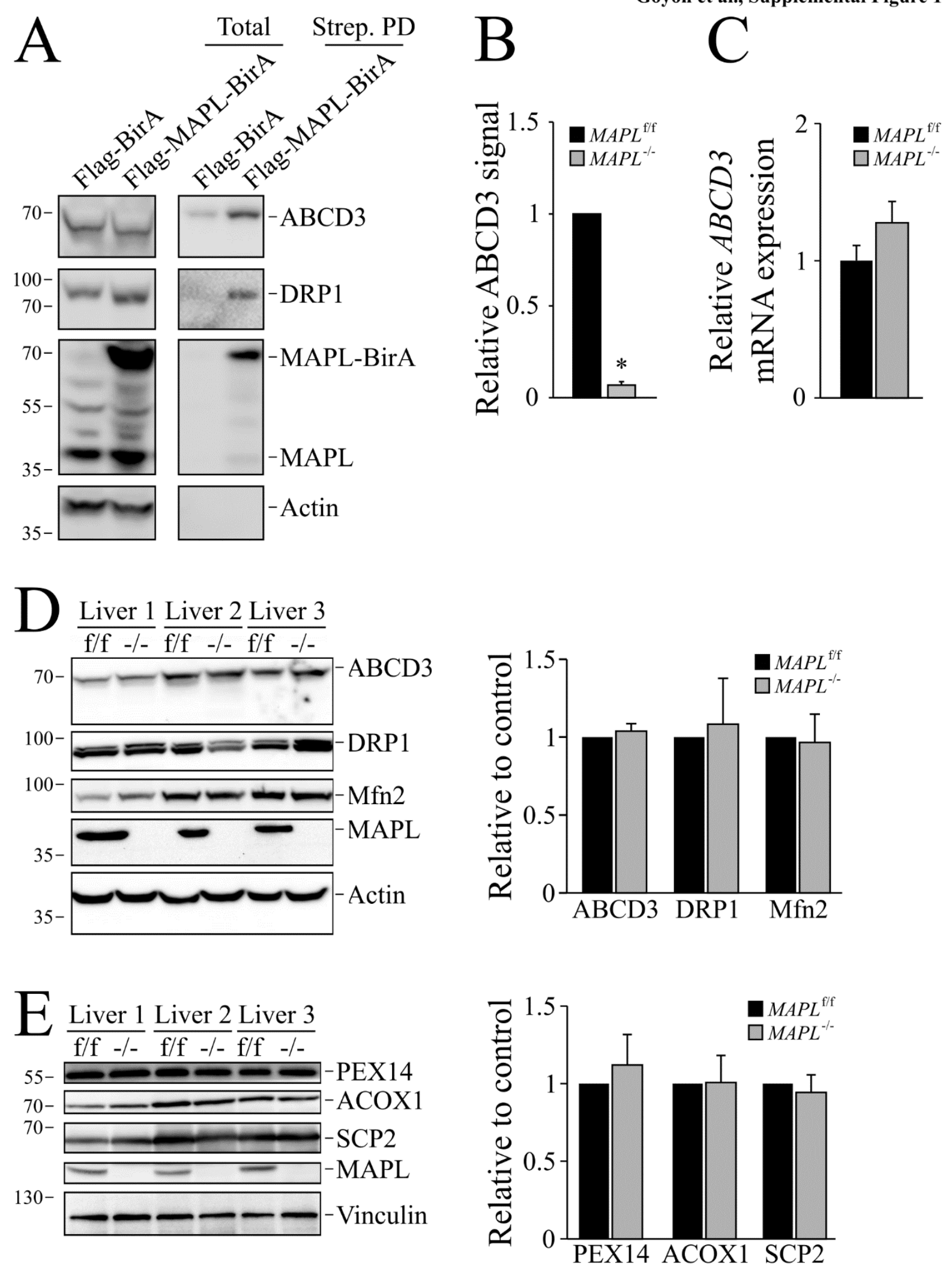


\section{Figure S1: MAPL SUMOylates ABCD3 and its absence alters ABCD3 complex assembly.}

1100 A. Representative western-blot of total lysate and streptavidin-beads pull-down fractions of 1101 HEK-293T-REX cells expressing Flag-MAPL-BirA or Flag-BirA (as control) incubated with biotin 1102 and probed for ABCD3, DRP1, MAPL and beta-actin.

1103 B. Quantification from 3 independent experiments of ABCD3 signals of the heavy membrane 1104 SIM-beads elution fraction (Figure 1C).

1105 C. qRT-PCR investigating $A B C D 3$ mRNA levels in livers of 4 different mice (2-month-old males).

1106 D. Representative western blots from whole cell liver extracts probed for ABCD3, DRP1 and 1107 Mfn2 (Left panel). ABCD3, Drp1 and Mfn2 signals were quantified ( $n=3$ for each strain, right 1108 panel).

1109 E. Representative western blots from whole cell liver extracts probed for PEX14, ACOX1 and 1110 SCP2 (Left panel). PEX14, ACOX1 and SCP2 signals were quantified ( $n=3$ for each strain, right 1111 panel).

$1112 * P<0.05 * * P<0.01 * * * P<0.001$ using $T$ test for two group comparison and multiple 1113 comparison correction (B,C,D,E) 
bioRxiv preprint doi: https://doi.org/10.1101/2022.03.03.482848; this version posted March 4, 2022. The copyright holder for this preprint (which was not certified by peer review) is the author/funder, who has granted bioRxiv a license to display the preprint in perpetuity. It is made available under aCC-BY 4.0 International license.

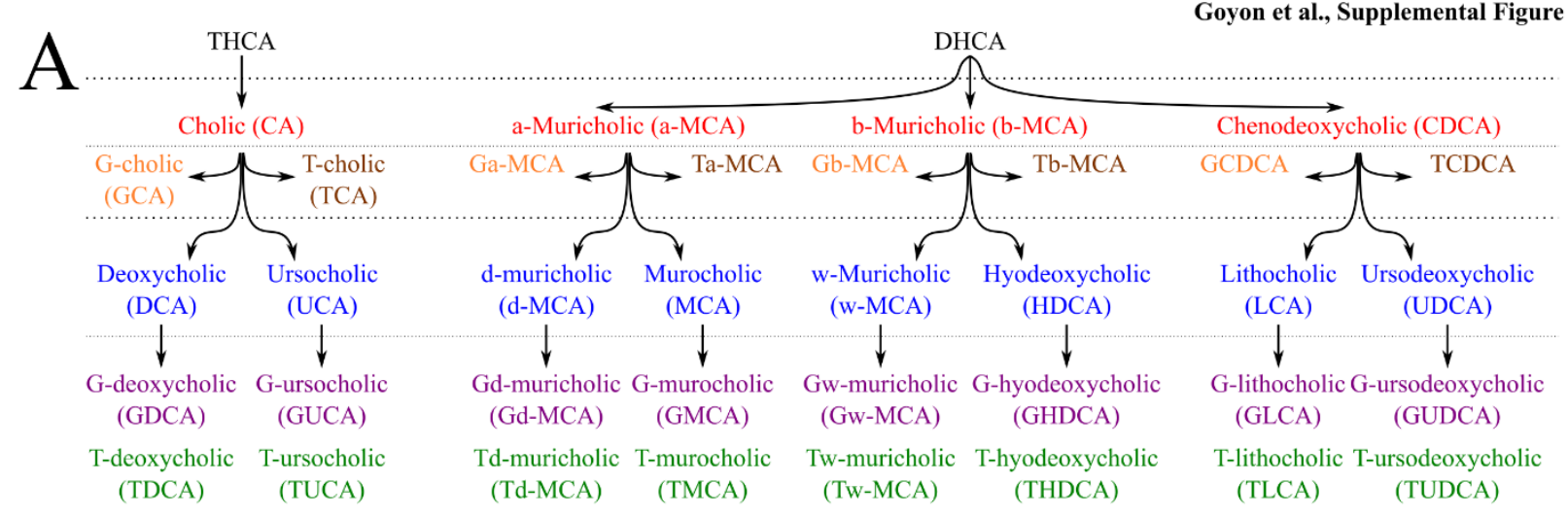

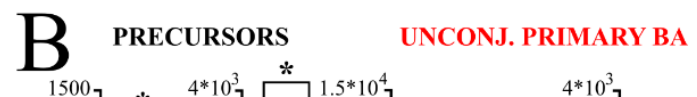

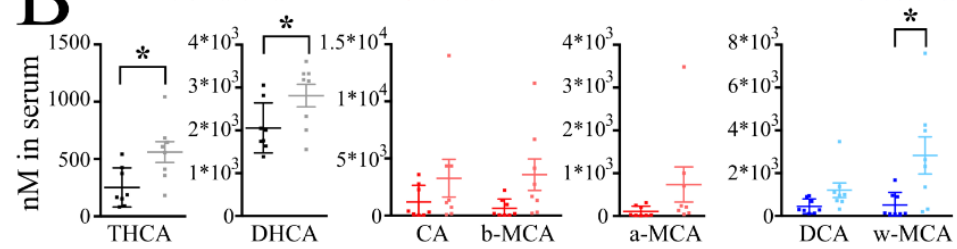

UNCONJ. SECONDARY BA TAURO-CONJ. SECONDARY BA
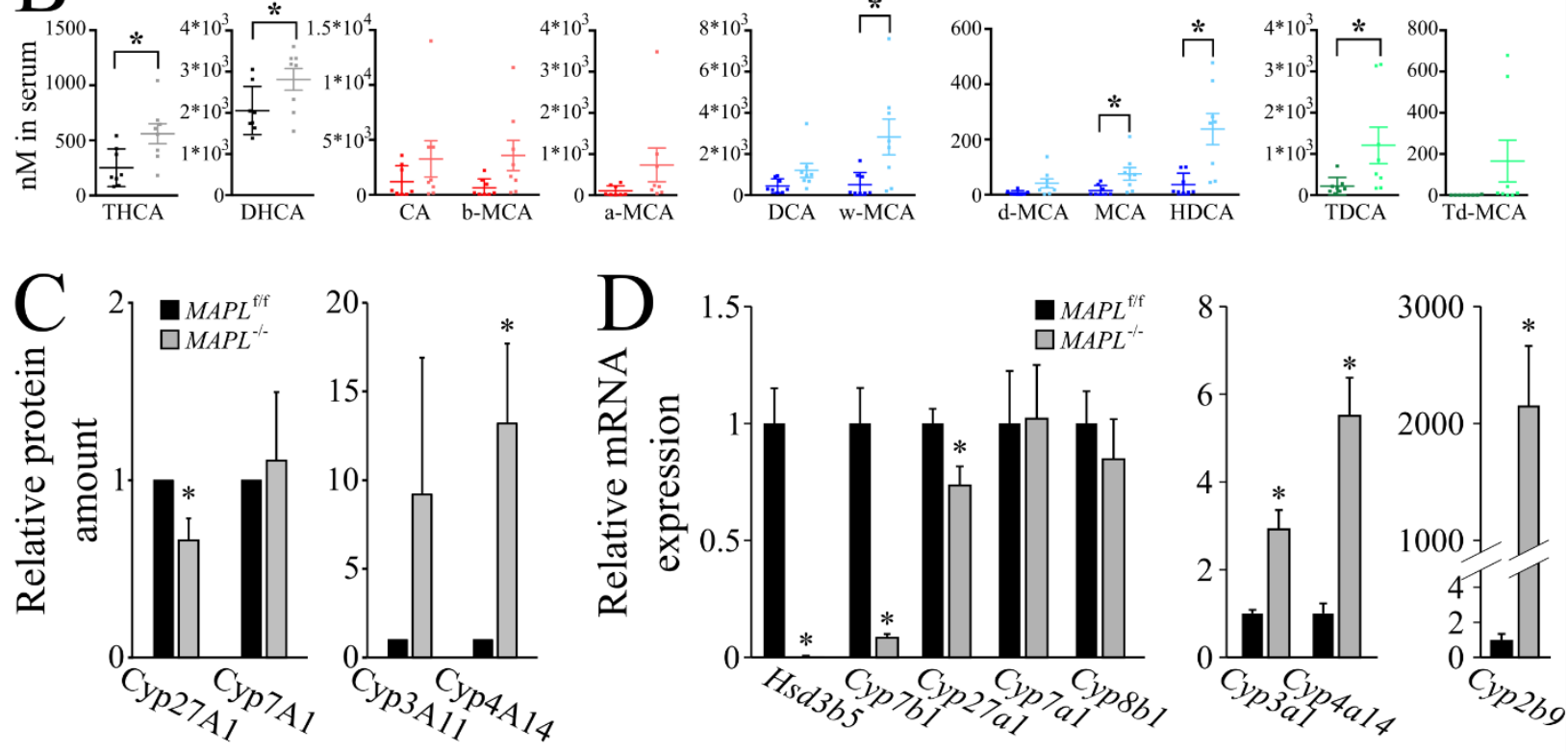

$\mathrm{E}$

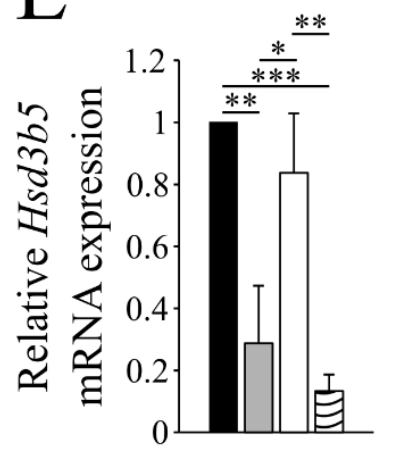

- $M A P L^{\mathrm{f} / \mathrm{f}}+\mathrm{Ad}-\mathrm{rtTA}$ $\square M A P L^{-/}+$Ad-rtTA

$\square M A P L^{-/}+$Ad-MAPL-Flag

日MAPL ${ }^{-1 /}+$ Ad-MAPL- $\triangle$ RING-Flag
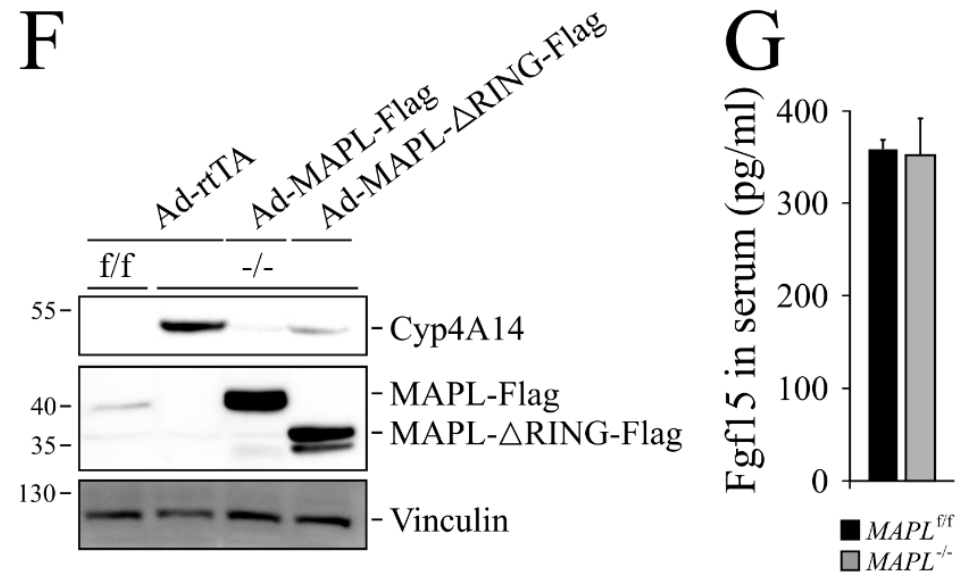

$\mathrm{H}$ FXR

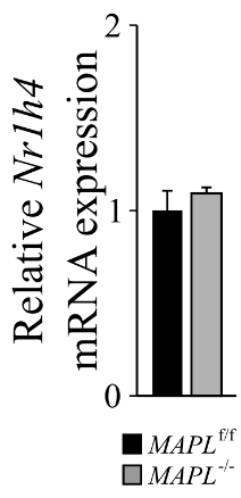


Figure S2: Loss of MAPL alters bile acid synthesis.

1121 A. A model depicting the generation of the main murine bile acids from THCA and DHCA (tri1122 and dihydroxycholestanoic acids) (G: glyco-; T: Tauro-).

1123 B. Bile acids precursors, as well as unconjugated and conjugated primary and secondary bile acids were quantified from serum ( $n=8$ for each strain, 2-month-old males). THCA and DHCA:

1125 tri- and dihydroxycholestanoic acid; CA: cholic acid; a-MCA, b-MCA, w-MCA and d-MCA: $\alpha-, \beta-$, $\gamma$ - and $\delta$-muricholic acid; DCA: deoxycholic acid; MCA: murocholic acid; HDCA: hyodeoxycholic acid; TDCA: taurodeoxycholic acid; td-MCA: tauro- $\delta$-muricholic acid.

1128 C. Quantification of CYP27A1, Cyp7A1, Cyp3A11 and Cyp4A14 of Figure 2G western blots (n=3

1129 for each strain).

D. Transcriptome analysis (Illumina) was validated by qRT-PCR on livers isolated from 3 different mice for each strain (2-month-old males).

E. qRT-PCR investigating $H s d 3 b 5$ mRNA levels in livers of rescued mice (in triplicate, $\mathrm{n}=7$ with 4 females and 3 males, $n=7$ with 4 females and 3 males, $n=5$ with 3 females and 2 males and $n=6$ with 3 females and 3 males, for MAPL f/f + rtTA, MAPL ${ }^{-/}+$rtTA, MAPL ${ }^{-1-}+\mathrm{MAPL}^{-F l a g}$ and MAPL $\mathrm{MA}^{-/}$ + MAPL- $\triangle$ RING-Flag, respectively, 2-3-month-old). G. Circulating Fgf15 was measured by ELISA ( $n=5$ and $n=6$ for MAPL ${ }^{f / f}$ and $\mathrm{MAPL}^{-/}$respectively, 2-month-old males). H. qRT-PCR investigating Nr1h4 mRNA levels (FXR) in livers of 3 different mice (2-month-old 1140 males). comparison correction 

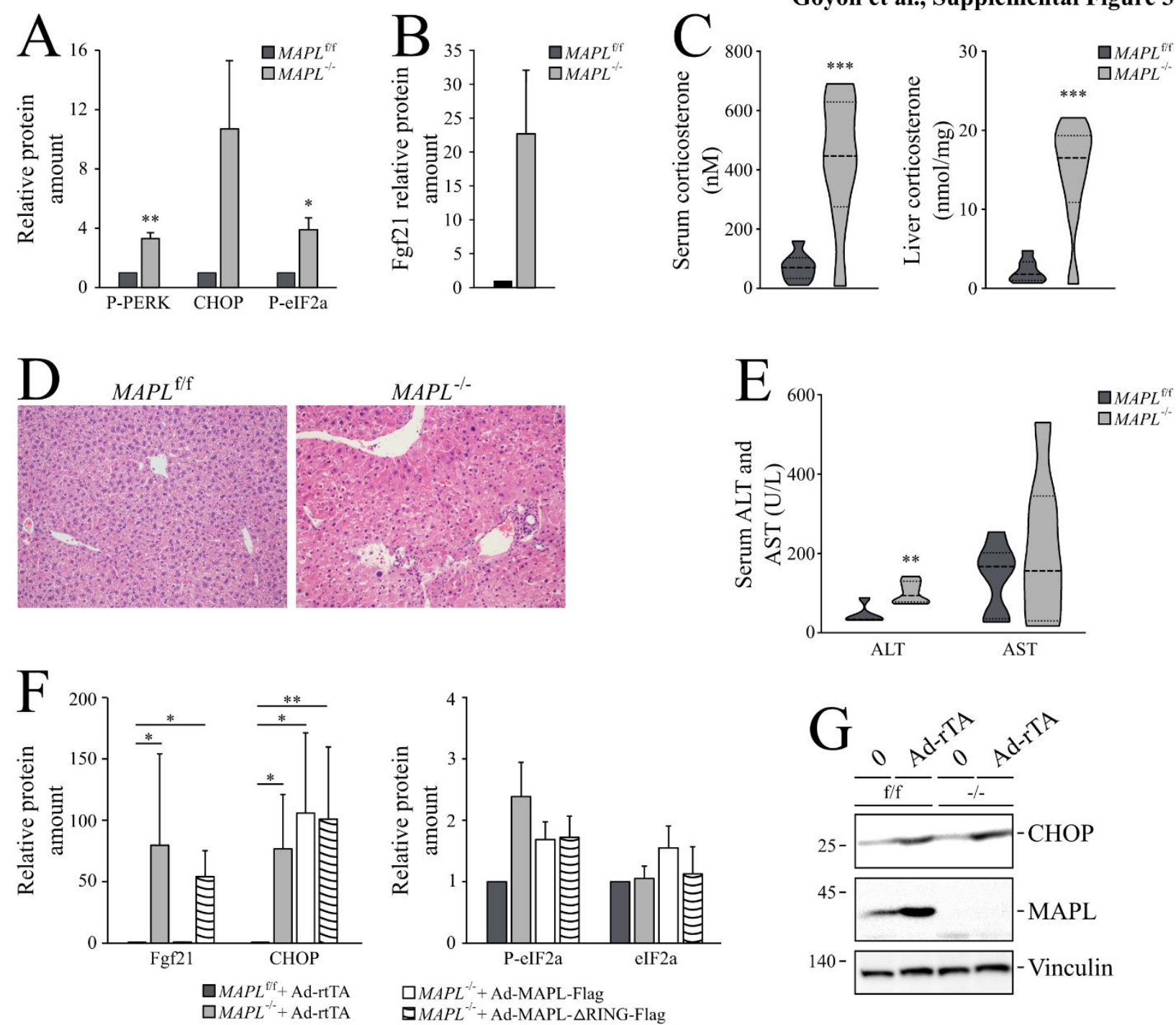

Figure S3: Loss of MAPL leads to hepatic ER stress, elF2 $\alpha$ activation and Fgf21 expression.

A. Quantification of phopsho-PERK, CHOP and elF2 $\alpha$ signals presented in Figure 3A and 3B western-blots ( $n=3$ for each strain).

B. Quantification of Fgf21 signals presented in Figure 3D ( $n=3$ for each strain).

C. Circulating and liver corticosterone levels were quantified as described in materials and methods ( $n=8$ for each strain, 2 month old males).

D. Representative pictures of livers from $M A P L^{f / f}$ and $M A P L^{-/-}$mice. Hematoxylin and eosin staining. 40X objective.

E. Levels of alanine transaminase (ALT) and aspartate transaminase (AST), markers of liver damage, were quantified and plotted from serum collected from 6 month old females $(n=5$ and $\mathrm{n}=6$ for $M A P L^{f / f}$ and $M A P L^{-/}$, respectively for ALT quantification and $n=6$ and $n=7$ for $M A P L^{f / f}$ and $M A P L^{--}$, respectively for AST quantification). 
1158 F. Left panel. Quantification of FGF21 signals presented in Figure $3 E\left(n=5,5,3\right.$ and 4 for $\mathrm{MAPL}^{\mathrm{f} / \mathrm{f}}$ + rtTA, MAPL ${ }^{-1-}+$ rtTA, MAPL ${ }^{-1-}+$ MAPL-Flag and $\mathrm{MAPL}^{-1-}+$ MAPL- $\triangle$ RING-Flag, respectively, 2-3

1160 month old). Right panel. Quantification of CHOP, P-elF $2 \alpha$ and elF2 $\alpha$ signals of Figure $3 \mathrm{~J}(n=4,4$, 11613 and 4 for MAPL ${ }^{\text {f/f }}+$ rtTA, MAPL ${ }^{-/}+$rtTA, MAPL ${ }^{--}+$MAPL-Flag and MAPL ${ }^{-/}+$MAPL- $\triangle$ RING-Flag, 1162 respectively, 2-3 month old).

1163 G. Representative western-blot of CHOP protein expression of livers isolated from MAPL ${ }^{\mathrm{f} / \mathrm{f}}$ and $1164 \mathrm{MAPL}^{-/-}$animals injected or not with the empty virus rtTA.

1165 comparison correction (A,B,C,E) or ANOVA for multiple group comparisons (F)

1168

1169

1170

1171

1172

1173

1174

1175

1176

1177

1178 

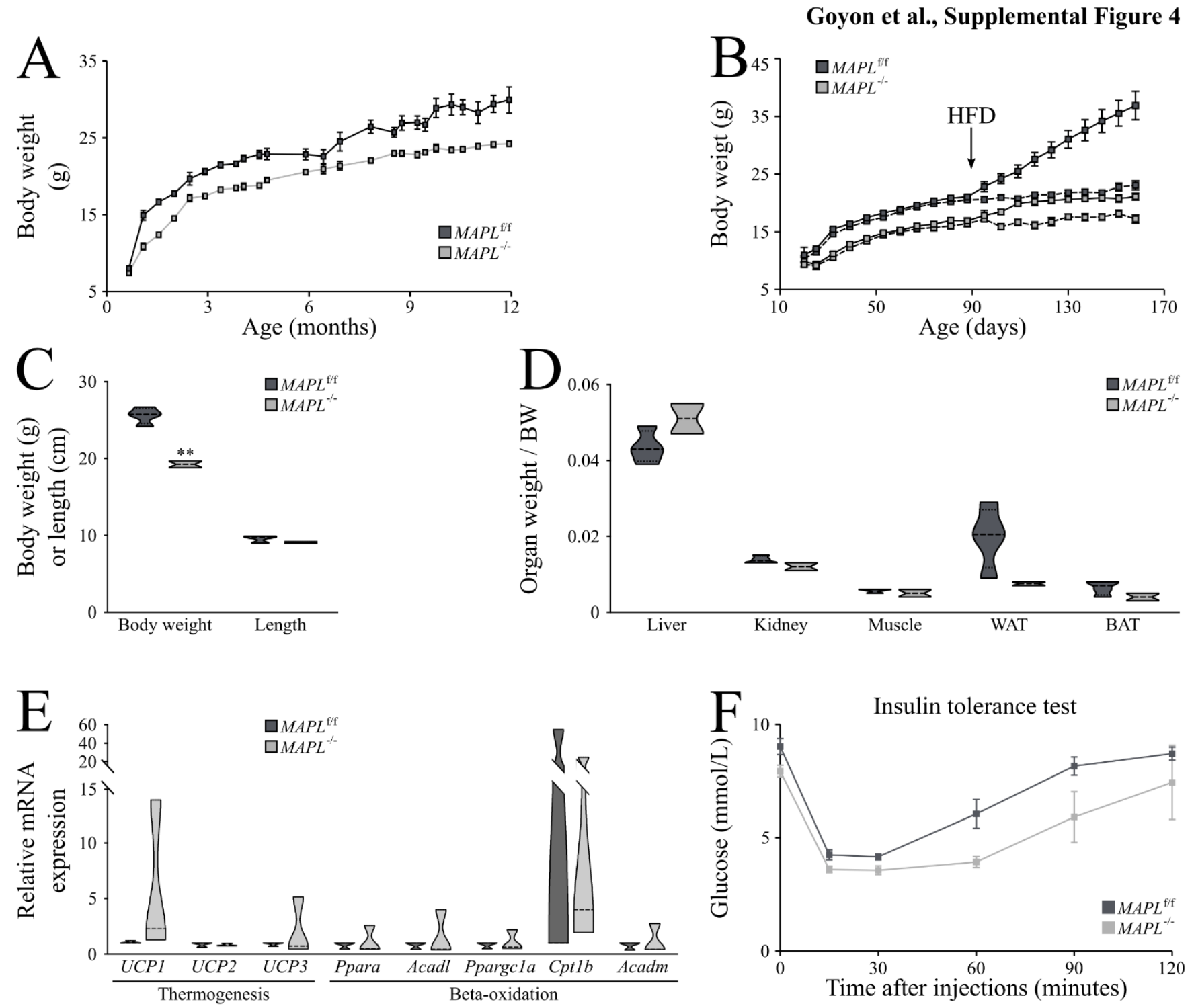

G

Glucose tolerance test

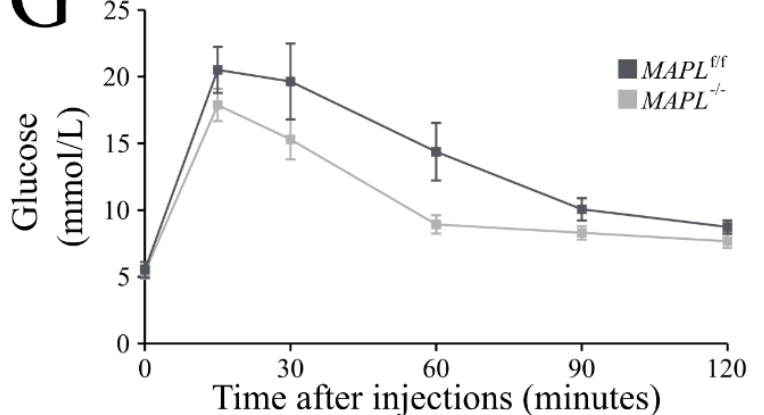

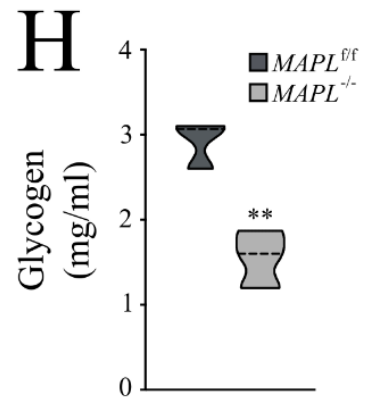




\section{Figure S4: $\mathrm{MAPL}^{-/-}$female mice are lean and resistant to weight gain.}

1184 A. Female mice fed with normal chow were weighed weekly; $\mathrm{MAPL}^{\mathrm{f} / \mathrm{f}}(\mathrm{n}=7)$ and $\mathrm{MAPL}^{-/-}(\mathrm{n}=10)$.

1185 B. $\mathrm{MAPL}^{\mathrm{f} / \mathrm{f}}$ and $\mathrm{MAPL}^{-/-}(\mathrm{n}=8$ for each strain) females were fed with normal chow for 5 months (dotted lines), or for 3 months followed by 2 months of $60 \%$ fat chow (solid lines, diet change indicated by HFD arrow).

1188 C. Body weight (g, left panel) and length (cm, right panel) of 7-month old MAPL ${ }^{\mathrm{f} / \mathrm{f}}(\mathrm{n}=4)$ and $\mathrm{MAPL}^{-1-}(n=2)$ female mice.

D. Wet weight of organs including liver, kidney, gastrocnemius muscle, epididymal white fat (WAT) and interscapular brown fat (BAT) isolated from 7-month-old MAPL ${ }^{\mathrm{f} / \mathrm{f}}(\mathrm{n}=4)$ or $\mathrm{MAPL}^{-/-}$ $(n=2)$ female mice.

E. White adipose tissue gene expression performed by qRT-PCR. $\mathrm{N}=3$, in triplicate, 2-month-old $1194 \mathrm{MAPL}^{\mathrm{fl} / \mathrm{fl}}$ and $\mathrm{MAPL}^{-/}$male mice.

F. Insulin tolerance test in $\mathrm{MAPL}^{\mathrm{f} / \mathrm{f}}(\mathrm{n}=7), \mathrm{MAPL}^{-/-}(\mathrm{n}=11)$ female mice. Insulin $(0.5 \mathrm{U} / \mathrm{kg})$ was injected intraperitoneally after a $2 \mathrm{~h}$ fast and blood glucose was measured at indicated times. G. Glucose tolerance test in $\operatorname{MAPL}^{\mathrm{f} / \mathrm{f}}(\mathrm{n}=7), \mathrm{MAPL}^{-/-}(\mathrm{n}=11)$ female mice. Glucose $(2 \mathrm{~g} / \mathrm{kg})$ was injected intraperitoneally after an overnight fast and blood glucose was measured at indicated times.

1200 H. Liver glycogen measured enzymatically in female $M_{A P L}^{f / f}(n=7), M A P L^{-/-}(n=11)$ mice. comparison correction or ANOVA for multiple group comparisons 


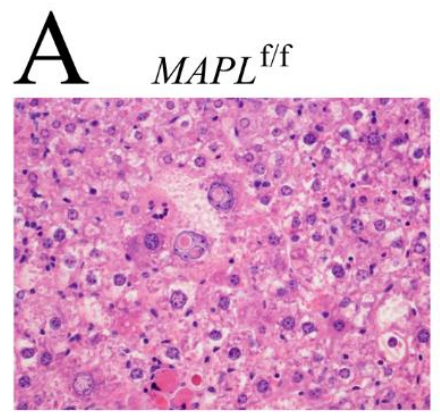

Goyon et al., Supplemental Figure 5
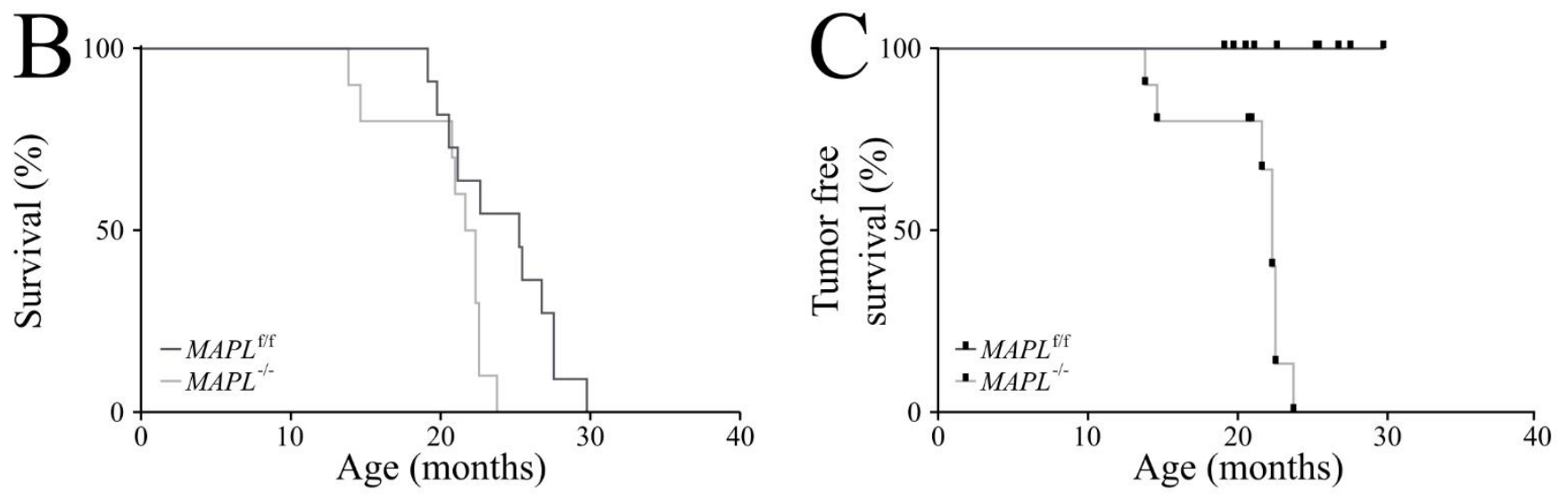

Figure S5: Spontaneous development of hepatocellular carcinoma in female MAPL deficient 1211 mice.

1212 A. Hematoxilin eosin staining of female $\mathrm{MAPL}^{\mathrm{f} / \mathrm{f}}$ and $\mathrm{MAPL}^{-/-}$livers.

1213 B. Survival curve of $\mathrm{MAPL}^{\mathrm{f} / \mathrm{f}}(\mathrm{N}=11)$ and $\mathrm{MAPL}^{-/-}(\mathrm{N}=11)$ female mice.

1214 C. Cancer free survival curve of $\mathrm{MAPL}^{\mathrm{f} / \mathrm{f}}(\mathrm{N}=11)$ and $\mathrm{MAPL}^{-/-}(\mathrm{N}=11)$ female mice. 
Supplementary Table 1: BiolD analysis of MAPL interacting proteins.

1220 MAPL-BirA*Flag BiolD results. Data are presented as spectral counts detected for each prey

1221 protein, as indicated. Two technical replicates were performed on each of two unique biological

1222 replicates (for a total of four MS analyses). Selection of preys was based on ProteinProphet

1223 confidence score $p \geq 0.85$ (FDR $<1 \%$ ) and SAINT Express score $\geq 0.9$. For control runs, only the

1224 highest four spectral counts (out of 16 runs) are shown.

1225

Supplementary Table 2: Quantification of bile acid species from liver and serum.

1227 Precursors, unconjugated and conjugated primary and secondary bile acids were quantified as

1228 described in materials and methods on liver and serum from 2-month-old males ( $n=8$ for each 1229 strain).

\section{Supplementary Table 3: Transcriptome analysis from liver.}

1232 Table presenting data from the Illumina analysis performed on 5-month-old males ( $n=3$, for 1233 each strain, in triplicate) as described in material and methods, summarizing genes with 1234 variations higher than 2 -fold (with a $p$ value lower than 0.05 ) implicated in different metabolic 1235 pathways. 